\title{
Guidelines for the monitoring of Osmoderma eremita and closely related species
}

\author{
Emanuela Maurizi ${ }^{1,2}$, Alessandro Campanaro ${ }^{2,3}$, Stefano Chiari ${ }^{1,2}$, \\ Michela Maura ${ }^{1,2}$, Fabio Mosconi ${ }^{2,4}$, Simone Sabatelli ${ }^{4}$, Agnese Zauli, ${ }^{1,2}$, \\ Paolo Audisio ${ }^{4}$, Giuseppe Maria Carpaneto'
}

I Università Roma Tre, Dipartimento di Scienze, Viale Guglielmo Marconi 446, 00146 Roma, Italia 2 Consiglio per la ricerca in agricoltura e l'analisi dell'economia agraria - Centro di ricerca Difesa e Certificazione, Via di Lanciola 12/a, Cascine del Riccio 50125 Firenze, Italia 3 Centro Nazionale per lo Studio e la Conservazione della Biodiversità Forestale "Bosco Fontana" - Laboratorio Nazionale Invertebrati (Lanabit). Carabinieri. Via Carlo Ederle 16a, 37126 Verona, Italia 4 Università di Roma "La Sapienza", Dipartimento di Biologia e Biotecnologie "Charles Darwin”, Via A. Borelli 50, 00161 Roma, Italia

Corresponding author: Emanuela Maurizi (emanuela.maurizi@uniroma3.it)

Academic editor: F. Mason | Received 12 March 2017 | Accepted 12 June 2017 | Published 28 August 2017

http://zoobank.org/A3960B98-1CC9-48B8-8053-12367871EF64

Citation: Maurizi E, Campanaro A, Chiari S, Maura M, Mosconi F, Sabatelli S, Zauli A, Audisio P, Carpaneto GM (2017) Guidelines for the monitoring of Osmoderma eremita and closely related species. In: Carpaneto GM, Audisio P, Bologna MA, Roversi PF, Mason F (Eds) Guidelines for the Monitoring of the Saproxylic Beetles protected in Europe. Nature Conservation 20: 79-128. https://doi.org/10.3897/natureconservation.20.12658

\begin{abstract}
Osmoderma eremita (Scopoli, 1763) is a saproxylic scarab beetle protected by the Habitats Directive in the European Union. The present paper is part of a special issue on monitoring of saproxylic beetles protected in Europe and starts with a revision of the current knowledge on systematics, ecology, ethology and conservation of $O$. eremita and its allied species, followed by experimental tests of different methods for monitoring its populations. Two methods were compared in several localities of central Italy: (1) the widely used pitfall traps into tree cavities and (2) black cross windows traps baited with a specific pheromone produced by male beetles. The first method, often used in northern and central Europe, did not give acceptable results in Italy probably because of the scarcity of veteran trees with large hollows. It could only be used successfully in areas where: 1) tree hollows were abundant, large enough and with sufficient amounts of wood mould for planting pitfall traps and 2) the team is composed of several operators in order to ensure the checking of at least 150 traps every two days during the whole period of mating activities (15 July-25 August). The second method, consisting of hanging 30 black cross window traps during the mating period and checking them every two days, turned out to be better for capturing a significant number of individuals but cannot be used every year because of the possible disturbance on mating activities of the species.
\end{abstract}

Copyright Emanuela Maurizi et al. This is an open access article distributed under the terms of the Creative Commons Attribution License (CC BY 4.0), which permits unrestricted use, distribution, and reproduction in any medium, provided the original author and source are credited. 


\section{Keywords}

Saproxylic beetles, old-growth forests, hollow trees, dead wood, trap sampling, Habitats Directive

\section{Introduction}

The hermit beetle, Osmoderma eremita (Scopoli, 1763), is a large saproxylic chafer (Coleoptera: Scarabaeidae: Cetoniinae) associated with hollow veteran trees of the European broadleaf woodlands. It is included in Annexes II and IV of the Habitats Directive (Council Directive 92/43/EEC of 21 May 1992 on the conservation of natural habitats and of wild fauna and flora). The Habitats Directive requires that Member States prepare, every six years, a report on the conservation status of the species listed in the Annexes. In order to facilitate the answer to this obligation, the Life Project "Monitoring of insects with public participation" (LIFE11 NAT/IT/000252: hereafter, MIPP) conducted experimental fieldwork to develop a standardised method for monitoring the saproxylic beetle species for the project: Osmoderma eremita (hermit beetle, Scarabaeidae), Lucanus cervus (European stag beetle, Lucanidae), Cerambyx cerdo (great capricorn beetle, Cerambycidae), Rosalia alpina (rosalia longicorn, Cerambycidae) and Morimus asper/funereus (morimus longicorn, Cerambycidae) (Mason et al. 2015).

The present paper is part of a special issue on the results for monitoring saproxylic beetles which are protected in Europe and it is dedicated to Osmoderma eremita. The paper starts with a significant revision of the current knowledge on systematics, distribution, ecology, ethology and conservation of Osmoderma eremita and allied species, mostly derived from a subsequent split of the species and hence worthy of the same protection level. Such a review is followed by the experimental test of methods for monitoring its populations.

\section{Systematics and distribution}

The genus Osmoderma, established in 1828 by Le Peletier de Saint-Fargeau and Audinet-Serville, is currently assigned to the superfamily Scarabaeoidea, family Scarabaeidae (scarab beetles) and subfamily Cetoniinae (fruit or flower chafers). Nevertheless, in many European scientific papers and databases produced in the second half of the last century, the subfamily was raised to family rank and Osmoderma was reported as a genus of the family Cetoniidae. This change in systematic arrangement caused some confusion in the documents of the Habitats Directive and is explained by the fact that some specialists, (i.e. authors of the most important works used for identification of the European scarab beetles (Balthasar 1963, Baraud 1977, 1992, Paulian and Baraud 1982, Martin-Piera and López-Colón 2000, etc.) revised the systematic subdivision, introduced by Westwood (1839), where these animals were divided into numerous families. Such extreme splitting classification was overcome by modern integrated studies of morphological and molecular analysis where the family Scarabaeidae was 
reconsidered in a wider sense (e.g. Lawrence and Newton 1995, Browne and Scholtz 1995, 1998, 1999, Scholtz and Grebennikov 2005, Smith et al. 2006, Ahrens 2006, Bouchard et al. 2011, Ahrens et al. 2014, McKenna et al. 2015).

Within the subfamily Cetoniinae, traditional taxonomy assigned the genus $O s-$ moderma to the subtribe Osmodermina (two genera) of the tribe Trichiini, a large clade of Cetoniinae that includes the widespread genera Trichius, Gnorimus and others (Howden 1964, Krikken 1978, Smetana 2006, Schoolmeesters 2016). However, a recent molecular study (Šípek et al. 2016a, 2016b) suggested closer affinities between Osmoderma and other fruit chafers, more than with the above-mentioned genera and thus concluding that it should be assigned to the tribe Cetoniini. Such great instability at higher levels of systematic classification is also reflected at both genus and species level, due to an extensive debate on nomenclature and taxonomy which has been on-going for many years (cf. Tauzin 1994a, 1994b, 1996, 2000, 2002, 2006, Sparacio 1994, 2000, Massa 1995, Gusakov 2002, Audisio et al. 2007, 2009, Zauli et al. 2016a), with implications also concerning the conservation priority of Osmoderma populations. Although the validity of the genus name became controversial when some authors (Ádam 1994, Gusakov 2002) asserted that priority was due to a formerly used epithet, Gymnodus Kirby 1827, the International Commission on Zoological Nomenclature decided to adopt the name Osmoderma by a special resolution based on the principle of prevailing usage and the need for stability (Smith 2004, Krell et al. 2006, Audisio et al. 2007, Barclay 2007, ICZN 2007). The debate at species level involved both taxonomy and nomenclature of the eastern populations, since Motschulsky (1860) put in doubt the terra typica of Osmoderma barnabita, a species he had formerly described in 1845 . Thus, from southern European Russia, the terra typica became eastern Siberia, setting off a series of subsequent taxonomic interpretations. Therefore, the name assigned to these populations changed over time according to different authors: O. lassallei septentrionale Tauzin, 1994, O. coriarius (De Geer, 1774) and then again O. barnabita (cf. Tauzin 1991, 1994a, 1994b, Gusakov 2002, Audisio et al. 2007, 2009).

At global level, the genus includes at least 12 species throughout the Holarctic Region (Howden 1964, Gusakov 2002, Smetana 2006, Audisio et al. 2007, Bezborodov 2016, Schoolmeesters 2016). The geographic range of the genus Osmoderma, such as the range of many deciduous forest-dwelling animals of the northern hemisphere, is subdivided into three disjunct sectors: northeastern and central United States of America (3 species according to Howden 1968), Europe with its Near East countries (4 in Europe, 1 in Anatolia, 1 in Georgia) and Far East Asia (3 species in NE China, S Siberia, Korea and Japan).

The North American sector includes mainly the potential range of the US eastern broadleaf deciduous forests and extends southwards up to the $35^{\text {th }}$ parallel, where two species occur sympatrically: O. eremicola (Knoch, 1801) and O. scabrum (Palisot de Beauvois, 1805). A third species, O. subplanatum Casey, 1915, unexpectedly lives in the Great Plains, probably restricted to fragmented woodlands along lake shores and the river basins of the Mississipi and Missouri. All three of them overrun the southern border of Canada to a limited extent. 
The three species living in the Asian Far East have recently been revised by Bezborodov (2016): O. davidis Fairmaire 1887, from Transbaikalia and NE China to Primorskii Territory and N Korea; O. caeleste (Gusakov 2002) from NE China, Primorskii Territory and N Korea; O. opicum Lewis 1887 from Primorskii Territory, N Korea and Japan. The different ranges of the three species overlap in the temperate broadleaf and mixed forests of the southern Primorskii Territory, near Vladivostok, where they live together and where they were also observed in the same tree (Bezborodov 2016). The range of $O$. davidis is wider than the other two species and reaches westwards to the forest-steppe ecotones on the border between Transbaikalia and Mongolia.

In order to address the great confusion in taxonomy and nomenclature of the European hermit beetles, a DNA-approach of species delimitation was attempted by Audisio et al. $(2007,2009)$ and resulted in the consideration of the occurrence of at least four species in Europe:

Osmoderma eremita (Scopoli, 1763) in most of western Europe;

Osmoderma barnabita Motschulsky, 1845 (sensu Audisio et al. 2007) in most of eastern Europe;

Osmoderma lassallei Baraud and Tauzin, 1991, endemic to northern Greece and European Turkey;

Osmoderma cristinae Sparacio, 1994, endemic to Sicily.

Genetic distance and parsimony analysis well supported the delimitation of two clusters, each formed by two species: the first cluster is restricted to western Europe (O. erem$i t a$ and $O$. cristinae) and the second one to eastern Europe (O. barnabita and O. lassallei) (Figure 1). The northern trait of the boundary between the two clusters divides Sweden (O. eremita) and Finland (O. barnabita), while the southern trait, still poorly delimited, crosses Germany, Austria and Slovenia (where both O. eremita and O. barnabita seem to occur) (Audisio et al. 2007, 2009, Landvik et al. 2013) (Figure 1). Within O. eremita, preliminary morphological analyses delimited a putative Italian subspecies, O. eremita italicum Sparacio, 2000 whose presence was, until the present time, verified for only a few localities in three regions of southern Italy (Campania, Basilicata and Calabria).

The morphological traits used for delimiting the above mentioned species and subspecies are poorly marked and subject to a significant variation. They mainly concern the reliefs on head and pronotum, as well as the shape of male genitalia (Figures 2, 3). The lack of well-differentiated outlines can generate a high degree of uncertainty when the populations living in the areas of contact between the ranges of the various taxa are studied, e.g. in central Europe and in the Balkans, due to intermediate phenotypes which make difficulties in the assignment of individuals to two neighbouring taxa.

An integrated approach to the Italian populations, based on morphological and molecular analyses (Zauli et al. 2016a), suggested that both the genetic distance (COI and AFLP markers) and morphological divergence (particularly the shape of male genitalia) support the validation of species rank for $O$. cristinae, despite the close relationship between this Sicilian endemic taxon and the widespread $O$. eremita. 


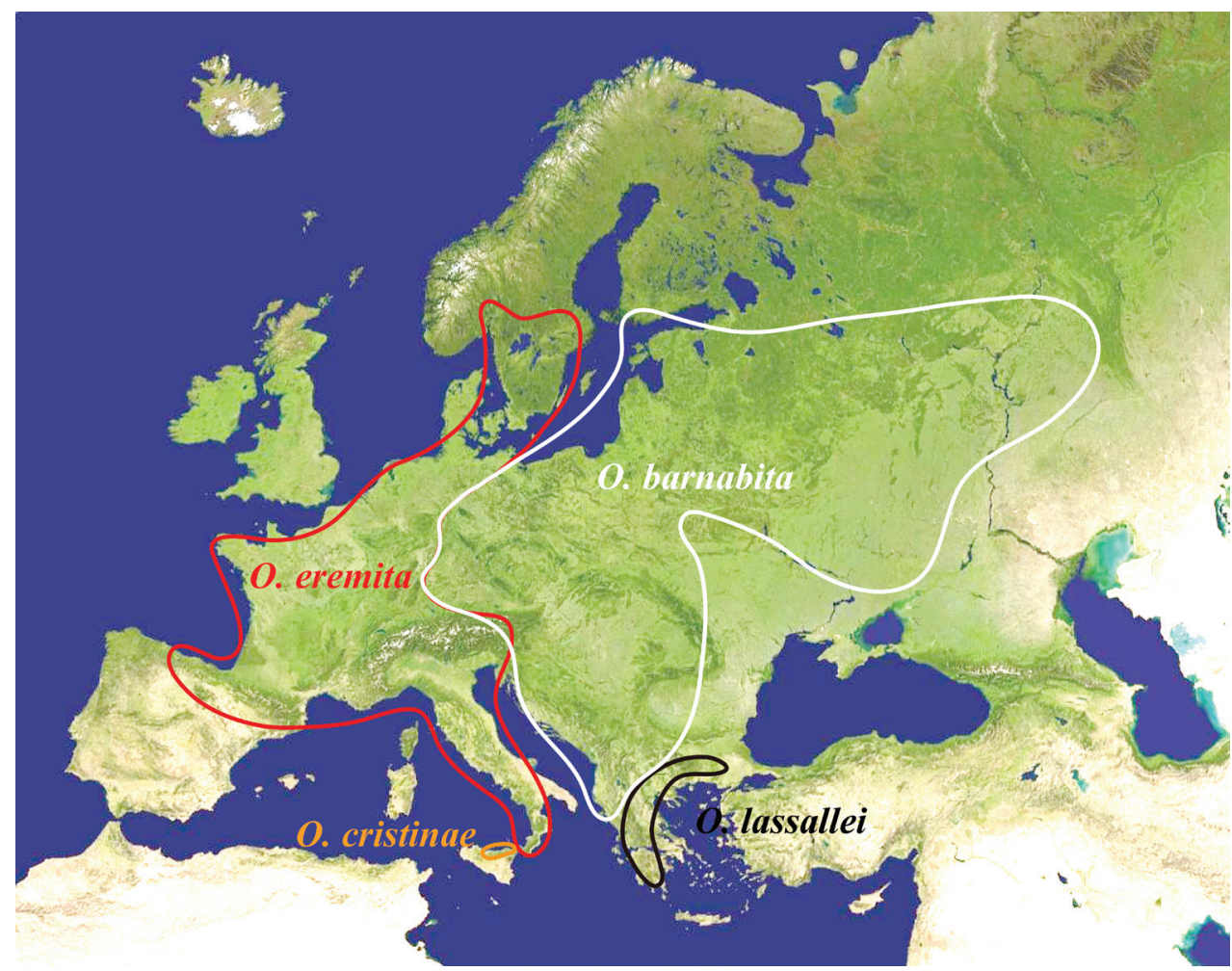

Figure I. Distribution map of the genus Osmoderma in Europe (from Audisio et al. 2009, modified) (prepared by M. Liu).

Additional poorly investigated taxa occur from the Balkan peninsula to the Caucasus mountains (apart from O. lassallei and O. barnabita): at least one undescribed species or semispecies, related to O. lassallei, in southern Greece (P. Audisio, P. Petrakis and G.M. Carpaneto, unpublished data); the rare O. brevipenne Pic, 1904, described from the Taurus Mountains, southern Turkey; O. richteri Medvedev, 1953, from Georgia, Caucasus (only two females captured until now).

\section{Morphology and comparison with similar taxa}

The genus Osmoderma includes the largest fruit chafers (Cetoniinae) of the European fauna (body length up to $36 \mathrm{~mm}$, head included; greatest width of elytra up to $19 \mathrm{~mm}$ ). The head is small in comparison with the body, with a clypeus broader than long. Antenna is 10 -segmented with a small terminal club formed by three short lamellae. The body is wide, suboval and more or less flattened dorsally. The prothorax is significantly narrower than the bases of the elytra, more or less convex, with lateral sides rounded or sharp-cornered just before the middle. The legs are strong, with moderately long tibiae 

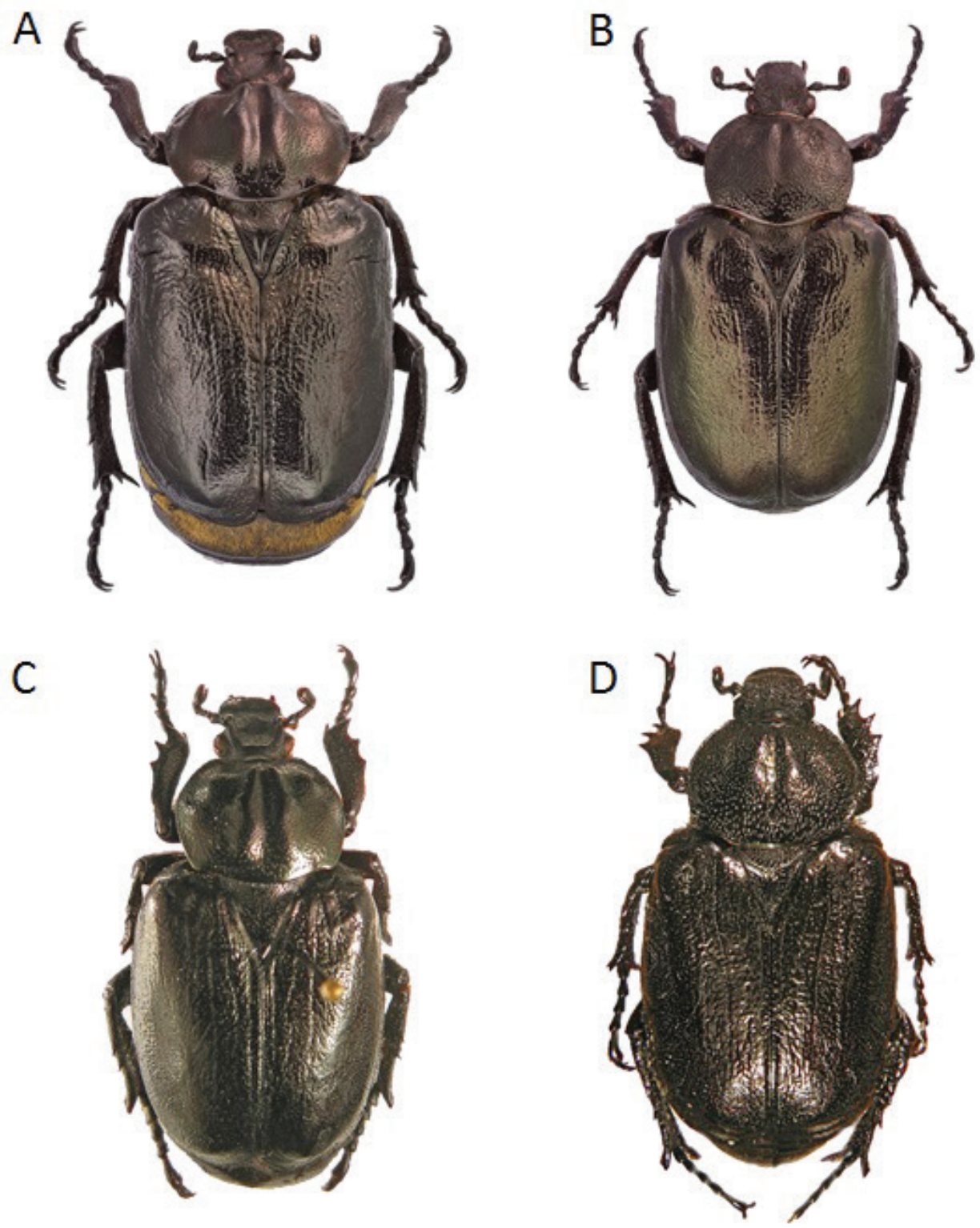

Figure 2. Habitus of Osmoderma in dorsal view. A O. eremita male B O. eremita female C $O$. cristinae male D 0 . cristinae female (photographs by A. Ballerio and M. Uliana, from Ballerio et al. 2010).

and short tarsi. Fore tibiae have three distinct teeth on their external side. The wings are well developed in both sexes. Colour is black to piceus or chestnut, often shiny with cupreous or green metallic lustre.

In the European species, males have a clypeus concave, more or less reflexed at apex, a slightly convex clypeo-frontal transition area and two lateral elevations above 

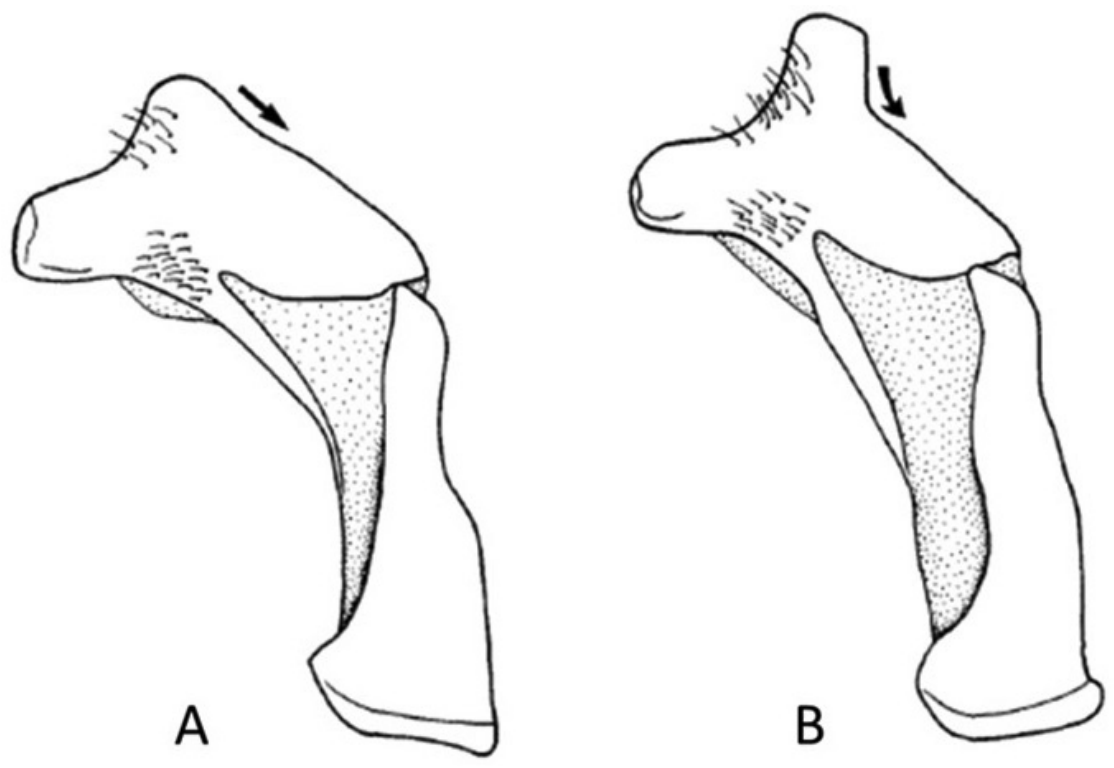

Figure 3. Lateral side of parameres, in $O$. eremita $(\mathbf{A})$ and $O$. barnabita $(\mathbf{B})$. The arrows indicate the lack or the presence of concavity under the protuberance (From Lüchte and Klausnitzer 1998, modified).

the antennal insertion that look like two horns. Females have a clypeus flat and not reflexed at apex, a tumid clypeo-frontal transition area and lack elevations at sides. Head surface is punctured in males and rugose in females. The pronotum of males has distinct basal angles, with lateral sides obtuse-cornered just before the middle; it is about one-third wider than long, strongly convex, with two distinct longitudinal carinae, parallel and separated by a more or less deep groove. The pronotum of females has basal angles rounded and an overall rounded outline, it is less convex than males and shows only vestigial ridges, almost vanished or reduced to two tubercles. Pygidium is large and strongly convex in males, smaller and slightly convex in female.

As already mentioned in the previous paragraph, the morphological traits used for delimiting the European species and subspecies are poorly marked and subject to significant variations. The morphological identification of Osmoderma is a task for specialists who have examined many specimens from different locations (in museums or other collections) and progressively acquired a deep knowledge of the intraspecific variation within single populations and throughout the geographic range of the species. Another problem is that the specimens occurring in many collections and museums cannot be used as a tool for making comparisons as they have often been improperly identified, owing to the extensive taxonomic confusion in the past decades. Luckily, the European species have different ranges and, in most cases, the populations can be simply assigned to a species by the locality. The problem arises when a locality is situated in the overlapping area between the ranges of two parapatric species, as in the case of $O$. eremita and O. barnabita in central Europe and the Balkans, where the possibility 
cannot be ruled out that they mated with each other. The less variable trait for separation of these two species is perhaps the shape of the parameres of the male genital organ (Krell 1997, Lüchte and Klausnitzer 1998, Sparacio 2000, Zauli et al. 2016a) according to the following key (see also Figure 3):

1. Parameres, on lateral side, show a strong upward protuberance like a triangular bump rounded at apex, followed by an almost straight or very slightly convex slope continuing up to their base.

O. eremita

2. Parameres, on lateral side, show a very strong upward protuberance like a square bump rectangular at apex, followed by a strong concavity and then a straight slope continuing up to their base. O. barnabita

The male genitalia also allow the separation of $O$. eremita and $O$. barnabita from O. cristinae, as the latter does not show a real upward extension on parameres but only a moderate swelling followed by a straight or very slightly convex slope continuing up to the base (Figure 4). However, genitalia shape cannot be used for monitoring populations because it requires dead specimens. In these cases, identification must rely on molecular analyses (e.g. mtDNA cytochrome C oxidase I, extracted from the femoral or tarsus muscle from a living individual) (Audisio et al. 2009).

All morphological characters used to separate the European species of Osmoderma are quantitative and change between them without a sharp difference; furthermore, they are subjected to significant variation and cannot give certainty in identification. The sexual differences in the $O$. barnabita/lassallei-group are less prominent than in the O. eremitalcristinae-group.

Non-expert operators engaged in searching the remains of Osmoderma in wood mould inside tree cavities, may find it hard to distinguish them from those of Gnorimus variabilis (Linnaeus, 1758). However, the remains of the latter are clearly smaller and slender, with proportionately longer and fine tarsi and middle tibiae are strongly recurved in males. Moreover, the outer side of the fore tibiae have two well developed teeth (instead of three teeth in Osmoderma), while the scutellum is shorter and halfcircle shaped (instead of the almost isosceles triangle-shaped scutellum of Osmoderma). Elytra of $G$. variabilis can have whitish spots on the dorsal surface.

The eggs of Osmoderma are globe-like and white, with a diameter of 4-5mm. Larvae are classified in the scarabaeiform type and usually named 'white grubs' or 'curl grubs' by applied entomologists. They are characterised by a stout and downward projecting (hypognathous) head and a large fat, white or blueish, C-shaped body (Hayes 1929, Boving and Craighead 1931, van Emden 1941, Ritcher 1966). In particular, the shape of hermit beetle larvae is very similar to that of other Cetoniinae, with whom they share the following characters: head small; labrum symmetrical; mandible with a ventral, oval, stridulatory area consisting of transverse ridges; maxilla with lacinia and galea fused and stridulatory teeth anteriorly directed; ninth and tenth abdominal segment fused together (Hayes 1929, Ritcher 1966, Shabalin and Bezborodov 2009). The 

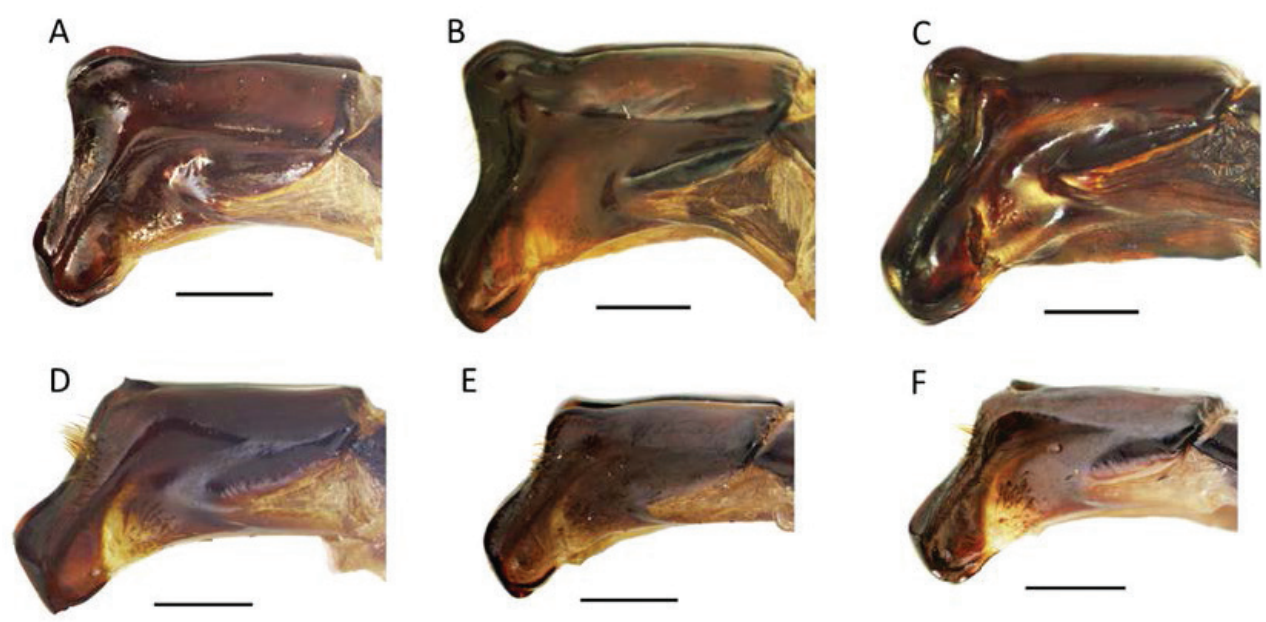

Figure 4. Lateral side of parameres, in O. eremita (A-C) and O. cristinae (D-F), showing intraspecific variation and difference on the parameres between the two species (photo by Federico Romiti).

head of the hermit beetle larvae is a red-orange capsule, with rugose punctures in the frons, a trilobed labrum and a pair of black and strong asymmetric mandibles. Legs are yellow-brownish and relatively short, each one ending with a wide-based, shortly subconical and blunted claw. The bristled ventral side (hereafter: 'raster', according to Boving and Craighead 1931) of the last abdominal segment lacks the longitudinal double row of spinules (hereafter: 'palidia', according to Ritcher 1966), which usually occur in Cetoniinae larvae (Korschefsky 1940) (Figure 5).

Larval characters are only used for the identification of wholly developed larvae (mainly belonging to the third stage, i.e. the last phase of their life cycle). A good combination of characters for separating hermit beetle larvae from those of all other European Cetoniinae is the following: 1) the absence of palidia across the raster, 2) the short, blunted and subconical terminal claw of tarsus and 3) the body size between 65 and $75 \mathrm{~mm}$, considering that the large larvae of Protaetia speciosissima are never longer than $65 \mathrm{~mm}$ (Korschefsky 1940). In fact, almost all European saproxylophagous fruit chafers which live in dead wood (i.e. Cetonia, Protaetia and Gnorimus) have distinct palidia and legs which end without a claw or with a normally elongate and slender claw (never thick, subconical and blunted) (Figure 6). Amongst the fruit chafer larvae occurring in the same habitat, only those of the genus Trichius lack palidia but are easily recognisable from Osmoderma because of their small body size (up to $40 \mathrm{~mm}$ long when mature), the normally elongate claw, the labrum rounded (instead of trilobed) and the last two abdominal segments well separated (instead of fused) (Shabalin and Bezborodov 2009).

The following key, mainly valid for third instar larvae was constructed by one of us (G. Carpaneto) and was based on information drawn from several authors (Hayes 1929, Böving and Craighead 1931, Korschefsky1940, Ritcher 1966, Klausnitzer and Krell 1997, Mico and Galante 2003a, 2003b, and Shabalin and Bezborodov 2009) as 
well as unpublished data. It may be useful for recognising larvae of hermit beetles from all other European Cetoniinae, with the aid of a pocket hand-held magnifier:

1. Tarsi ending with a claw (long or short, sharpened or blunted) ..................2

- Tarsi rounded apically, without claws ...................................................... 4

2. Tarsal claws slender, more or less sharpened and recurvate. Ninth and tenth abdominal terga separated in two single dorsal units. Raster with or without palidia. Anterior margin of labrum not distinctly trilobed, almost straight or slightly emarginate in the middle. Larvae in dead wood, up to $60 \mathrm{~mm} \ldots \ldots . .3$

- $\quad$ Tarsal claws neither sharpened nor recurvate, but like a black, short and thick conus with a large base and a blunted apex. Ninth and tenth abdominal terga fused into a single dorsal unit. Raster without palidia. Anterior margin of labrum distinctly trilobed. Larvae in dead wood, up to $75 \mathrm{~mm}$ long.

Osmoderma

3. Raster with two distinct palidia forming an oval Figure. Larvae in dead wood, up to 50 or $60 \mathrm{~mm}$ long, according to the species .......................... Gnorimus

- $\quad$ Raster without palidia. Last abdominal segment normally shaped. Larvae in dead wood, up to $40 \mathrm{~mm}$ long............................................................ Trichius Raster without palidia. Last abdominal segment ends with a pair of rounded areas delimited by a slight wrinkle. Larvae in dead wood, up to $25 \mathrm{~mm}$

Valgus

4. Larvae small (up to $25 \mathrm{~mm}$ ), amongst the roots of herbaceous plants

Oxythyrea and Tropinota

- Larvae large $(25-65 \mathrm{~mm})$, amongst plant roots, humus and dead wood, according to species

5

5. Raster with two well distinct palidia, each formed by18-28 spinules (mostly 22-24). Larvae up to $45 \mathrm{~mm}$ long....

Cetonia

- $\quad$ Raster with two well distinct palidia, usually formed by less than 22 spinules (usually 14-20, exceptionally up to 26 in the rare $P$. fieberi). Larvae, up to $65 \mathrm{~mm}$ long.

Protaetia and Aethiessa

Non-expert operators may have difficulty in recognising the larvae of hermit beetles from those of the other two large and widespread scarab beetles occurring in deadwood i.e.Oryctes (Scarabaeidae Dynastinae) and Lucanus (Lucanidae Lucaninae). Apart from microscopy characters involving antennae and mouth parts, often very hard to detect during the fieldwork, the larva of Oryctes is easily distinguished because its last abdominal segment is divided into two halves by a transverse narrowing, so that, in dorsal view, the abdomen seems to be formed by ten clearly observed segments. On the other hand, the larva of Lucanus is immediately recognisable by the abdominal terga not plicate, the longitudinal anal slit (instead of the transverse anal slit of Osmoderma and other Cetoniinae), the large but much narrower and elongate abdominal spiracles (see Bardiani et al. 2017) and the stridulating organs consisting of a series of teeth on 

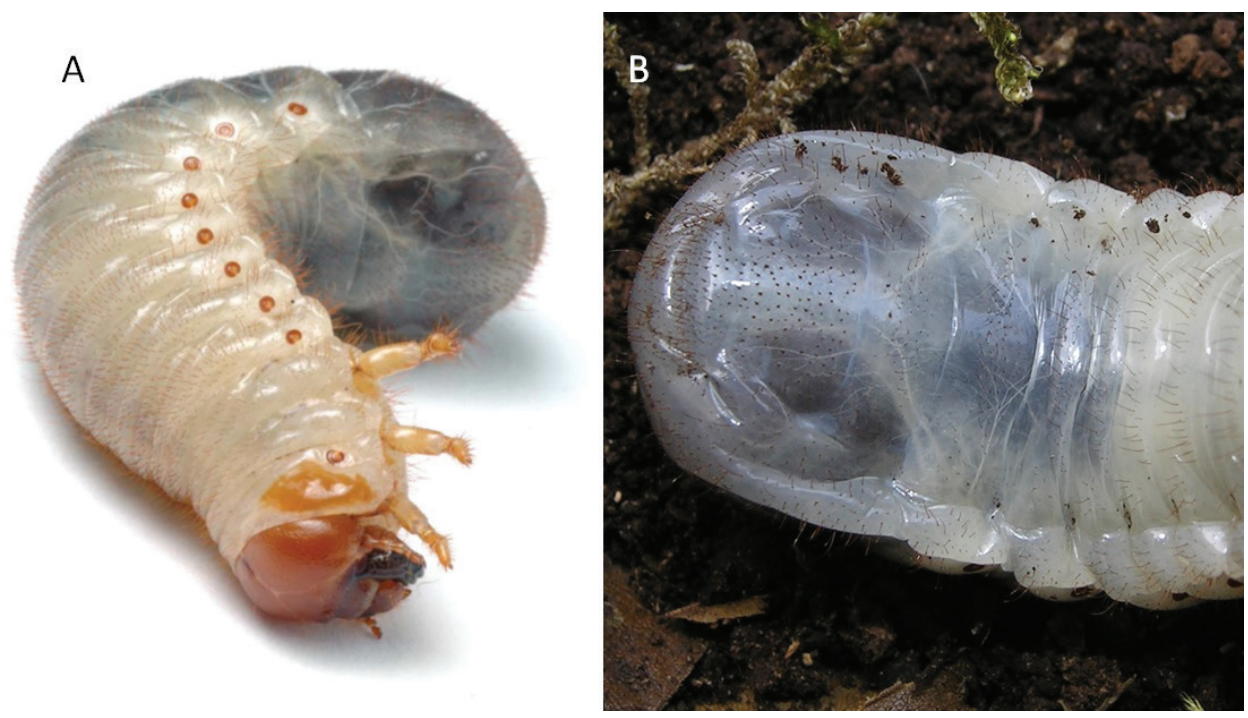

Figure 5. Larva of Osmoderma eremita. A Habitus and B Raster (ventral spiny area of the last abdominal segment). Note the lack of the palidia (the two longitudinal series of spinules occurring in the raster of most fruit chafers) and the end of the legs provided with a short and stout claw (see text for detailed explanation). (A photo by Sonia Dourlot, from Dubois 2009 B photo by Benjamin Calmont).

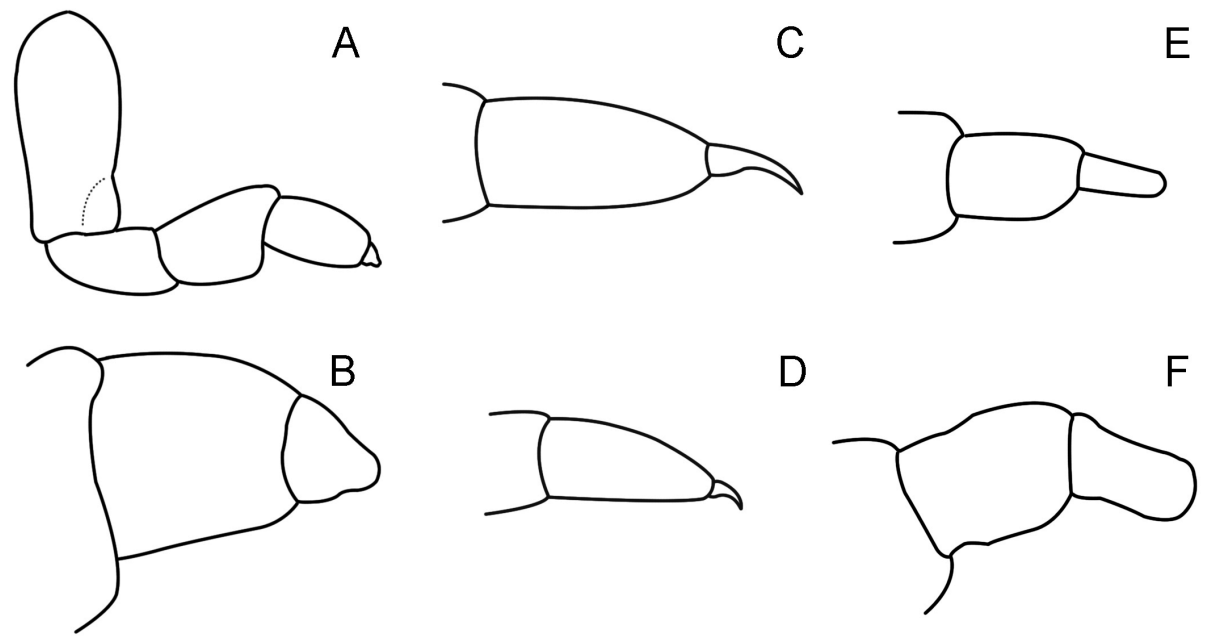

Figure 6. Shape of the terminal claw in European fruits chafer larvae. A leg of Osmoderma eremita B last two segments and claw of $O$. eremita $\mathbf{C}$ idem of Gnorimus variabilis $\mathbf{D}$ idem in Trichius fasciatus $\mathbf{E}$ last three segments in Cetonia aurata $\mathbf{F}$ last three segments in Protaetia cuprea (outlined by Federico Romiti).

second and third pairs of legs (instead of being present on the ventral side of mandibles and dorsal side of maxillae as in Cetoniinae). 


\section{Life cycle, food and chemical ecology}

The freshly laid egg of Osmoderma is globe-like and opaque white but, after 2-3 weeks, it becomes yellowish and doubles its size, reaching a diameter of $4-5 \mathrm{~mm}$. Each female lays 20-80 eggs deeply in a tree cavity, between the inner wall and the wood mould, protected by a flexible coating of wood pulp and a variable number of larvae (from 12 to 18 ) hatch after 14-20 days. The newly hatched larvae measure just $6 \mathrm{~mm}$ but they grow quickly, feeding on decaying wood and its mixture of rot-causing fungi. Larvae go through three different instars (L1, L2 and L3) across a developing time of 2-4 years and overwinter at their first or second instar, depending on the oviposition date and local microclimatic conditions (Tauzin 1994, Luce 1996, Schaffrath 2003a, Ranius et al. 2005). Laboratory and field studies conducted in Poland by Pawłowski (1961) showed that feeding activity of the larvae took place when the average daily temperature exceeded $13^{\circ} \mathrm{C}$ and they developed after three or four years. On the whole, the larvae were active only 30 weeks per year. Therefore, hibernation and developing time are directly affected by the temperature of the microhabitat in either tree hollows or vivarium. Similar field and laboratory observations over 3-4 years of development were made in other countries, such as Russia, Germany and Latvia (Nikitsky et al. 1996, Schaffrath 2003a, D. Telnov, in Ranius et al. 2005), while a shorter life cycle was reported for specimens kept indoors under favourable conditions without spending periods of feeding inactivity (M. Uliana, pers. comm. 2016). According to Dubois (2009), intra-clutch variation occurs in the development time of $O$. eremita: larvae hatched from the clutch of one female were bred in the same conditions and finished their development after two years (two males) and three years (10 males and one female) respectively. Such variation could be genetically based and may have a role in minimising inbreeding by avoiding mating between siblings.

At the end of the second or third summer, usually in September, when the third instar larva has reached its full development $(75 \mathrm{~mm}$ long), it builds an oval-shaped cocoon by clumping fine wood debris with its salivary and faecal secretions. Within this protecting case, the larva spends its last winter and then transforms into a pupa in the spring (normally in May) and into an adult (June) (Tauzin 1994). The emergence of the adults occurs in July and in early August, when many individuals show a shiny integument suggesting they had just emerged from the cocoon.

Tauzin $(1994 \mathrm{~b}, 2005)$, who reared O. eremita in the laboratory, observed that, in the case of mating, the lifespan of males was very short (10-20 days), while females lived for more than 90 days. Nevertheless, some males fed in captivity reached lifetimes of 90 days (Schaffrath 2003a) and a field study conducted on a Swedish population suggested males and females have the same life-time, with a maximum of about one month (Ranius 2001). Although hermit beetles seem unable to survive in natural habitats after the arrival of autumn, a hibernating adult female has once been found in January in the forest of Fontainebleau, France (Tauzin 1994b). The last observation seems to suggest that, under favourable conditions, females may have a longer lifespan and take advantage of the opportunity for increasing their breeding success, 
as evidenced by field research on other beetles, e.g. the longhorn beetle Morimus asper (Rossi de Gasperis et al. 2016).

The seasonal activity of the adults is correlated with climatic factors, such as altitude, latitude and habitat type. In Sweden, the adults are active from July to September, while in central and southern Europe, there have been several observations in May-June and even a few at the end of April (Stegner 2002, Schaffrath 2003a, Ranius et al. 2005, Vignon 2014). In France, the adults are active from the end of June to the end of August, with an emergence peak between 10 and 15 July (Vignon 2014). In Italy, the activity period is mostly from early June to mid-August with peaks in July (Carpaneto et al. 2010, Chiari et al. 2012, 2013a, 2013b, Giangregorio et al. 2015). In Valtellina (Lombardia, N Italy, Sondrio province), an emergence peak and an activity period, almost identical to those above reported for France (Vignon 2014), were observed during several years, with peaks of activity in the second half of July (P. Audisio, unpublished data). It may be concluded that, on the whole range of the species, phenology is from the end of April to September, but local variations occur due to different regimes of temperature and rainfall. However, most records were usually made from early July to early August.

One or two days after their emergence, the males of the genus Osmoderma start to emit a strong odour which can be perceived by humans at a distance of several metres, reported by French entomologists of the $19^{\text {th }}$ century as "cuir de Russie", namely Russian leather (Latreille et al. 1825). This odour is a male-produced sexual pheromone which attracts females and induces them to gather into the tree hollow occupied by a male. Chemical analysis identified this compound as $(R)-(+)-\gamma$-decalactone (Larsson et al. 2003, Svensson et al. 2003, 2004, Zauli et al. 2014). Ecological investigations showed that this chemical is also an attractant for females of the rusty red click beetle, Elater ferrugineus Linnaeus, 1758, a large click-beetle whose larvae live in hollow trees and feed on the immature stages of other saproxylic insects, mostly those of fruit chafers, with a special preference for hermit beetles. Therefore, click-beetle females use the sexual pheromone of the hermit beetle males as a kairomone in order to lay eggs in suitable tree cavities, already inhabited by the favourite prey for their offspring (Svensson et al. 2004, Larsson and Svensson 2009, 2011, Zauli et al. 2014, 2016c). Field trials, scent collection and biochemical analysis on $O$. barnabita and $O$. cristinae, showed that these species use exactly the same sex pheromone compound as $O$. eremita, demonstrating a strong conservation of this sexual trait within the genus throughout Europe (Landvik et al. 2015, Zauli et al. 2016a). Besides, as suggested by Svensson et al. (2009), the maleproduced pheromone in Osmoderma beetles may function as a territorial signal instead of a classical sex pheromone used for species discrimination and the selection pressure to change the signal may be weak or absent. From a conservation perspective, the use of (R)- $(+)-\gamma$-decalactone by allied species facilitates large-scale monitoring of the hermit beetles in Europe since it can be performed with the same target compound.

Many authors have indicated this scent to be similar to fermented fruit (peaches, plums or apricots) on which the adults were reported to feed. The French vernacular name "pique-prune" (= who picks the plum) (Vignon 2006) and the German one 
"Aprikosenkäfer" (Ranius et al. 2005) are surely related to this odour and/or to the popular knowledge that this species likes to feed on plums, apricots and other fruit of the rose family. However, the feeding activity of adult hermit beetles in nature has been rarely observed by entomologists. Ranius et al. (2005) revised the scarce information occurring in literature and gathered some unpublished data on this subject. Literature data reported some findings of the species on sap flows of broadleaf trees in Germany, Poland, Estonia and Russia, as well as a few observations in the laboratory where some specimens were fed with apples and bananas (Schaffrath 2003b). Unpublished data gathered by Ranius et al. (2005) included field observations on flowers of Leucanthemum sp. and Viburnum sp.in Croatia, on flowers of Sambucus nigra in Spain, on unidentified umbelliferous plants in Germany and on ripe yellow plums (Prunus sp.) in Poland. Another field observation was reported for central Italy by Chiari et al. (2013b) and concerned a radio-telemetered female that flew out of a cork oak forest and covered a distance of almost $1500 \mathrm{~m}$ before landing in an olive grove and staying at least one hour from $1300 \mathrm{~h}$ to $1400 \mathrm{~h}$, to eat an overripe apricot (Prunus armeniaca) which had fallen on the main tree fork. After all, the popular French name "piqueprune" and the similarity in the odour of plums and pheromones cannot be entirely due to chance: the link between this species and Prunus fruits should be thoroughly investigated, even to evaluate the needs of the species for its survival in protected areas.

\section{Habitat requirements and use of space}

The primary habitat of hermit beetles consisted of broadleaf old-growth forests with an abundance of hollow trees and dead wood. In particular, the species seems to prefer areas where the canopy is not dense because of the age of the plants and the occurrence of open space left by the fall of veteran trees. In fact, according to many literature data and the authors' long personal experience, hermit beetles are saproxylophagous species whose larvae meet their habitat and food requirements in tree cavities rich in wood mould. Nevertheless, as it is more than a strictly forest dwelling species, the hermit beetle seems to be an ecotonal species of the forest edge and clearings which can be found in any context where there are old hollow trees, not only in mature forests but also in the agricultural and urban landscapes. In contrast to logs and snags, live hollow trees provide long-lasting resources (Ranius and Nilsson 1997) and a specific abiotic environment characterised by stable temperature, suitable moisture conditions and increased $\mathrm{pH}$ values (Müller et al. 2014). Owing to the alteration of natural forests by commercial management and the consequent rarity of hollow trees, the hermit beetles disappeared in many apparently suitable broadleaf forests but survived in artificial habitats, such urban parks, wooded grasslands, old orchards and tree rows along channels or country roads, even if embedded in unsuitable cultivated environments (Vignon et al. 2004, Baratelli 2004, Dutto 2005, Ranius et al. 2005, Oleksa 2007, Carpaneto et al. 2010, Giangregorio et al. 2015). Many populations of hermit beetles in France live in chestnut orchards and in the hedgerow network, where the number of old trees is 
higher than in forests due to local management practices (Vignon and Orabi 2003, Vignon et al. 2004, Vignon 2006, 2008, 2015). These artificial environments represent 'habitats of substitution' for $O$. eremita in France and are considered very important for its survival in areas where old-growth forests are extremely reduced or absent.

The altitudinal range of the hermit beetle varies from sea level (evergreen forest dominated by holm oak, Quercus ilex or cork oak, Q. suber) up to almost $1400 \mathrm{~m}$ (mountain forests of beech tree, Fagus sylvatica), through all intermediate altitudinal belts (covered by mixed deciduous forests and woodlands of Quercus spp., Acer spp., Fraxinus spp., Tilia spp., Ulmus spp., Carpinus spp., Salix spp., Populus spp., Betula spp., Alnus spp., Castanea sativa etc.) (Ranius et al. 2005). However, an adult male of Osmoderma eremita ssp. italicum was recently collected in southern Italy (Mount Pollino Massif, Calabria) at 2000m in a hollow beech (A. Mazzei, pers. comm. 2016). Larvae can live in dead wood of both deciduous trees (oak, beech, maple, ash, lime, elm, hornbeam, willow, poplar, birch, alder, chestnut, apple, pear, plum, mulberry) and evergreen trees (holm and cork oak) and no clear preference was demonstrated for each of these species according to most observers (Schaffrath 2003a, 2003b, Tauzin 2005, Ranius et al. 2005, Chiari et al. 2014). Some scattered notes exist on the local association of hermit beetles with coniferous trees (Taxus, Pinus and Abies) but such information needs to be verified.

Hermit beetle larvae usually occur in hollow but still living, standing trees but they have also been found in dead standing trees as long as the dead wood is able to retain a suitable degree of moisture (Rainus et al. 2005). More rarely, the species has been observed in felled tree trunks or in stubs but it mainly occurs after a recent cut. The age of habitat trees suitable for hermit beetles depends on the features of wood. Fastgrowing species such as poplars (Populus spp.) and willows (Salix spp.) may harbour hermit beetles when they are only a few decades old (Schaffrath 2003a), while fruit trees are usually 80-100 years old (Stegner 2002). According to Ranius et al. (2005), slow-growing trees like oaks are 150-400 years old in Sweden, while the pollarded trees of the same species in France are only 70-120 years (Vignon and Orabi 2003). Usually, if suitable hollow trees are abundant and rich in dead wood, the local populations of hermit beetles may consist of a high number of individuals, even where the forest surface is reduced.

Despite widespread opinion supporting the extreme polyphagy of hermit beetles, detailed studies by larval sampling in wood mould showed that these insects have preferred tree species at the local level. The northern-most populations of Osmoderma $(O$. eremita in Sweden and O. barnabita in Finland) exploit mainly the huge trees of pedunculated oaks (Quercus robur) which form small stands in the agricultural landscape (Ranius et al. 2005, Landvik et al. 2015). Across a total of 192 hollow trees examined by Landvik et al. (2015) in Finland, they found signs of O. barnabita in a total of 62 trees (i.e. in 32\% of the trees examined): $67 \%$ of Q. robur, $21 \%$ of Tilia spp. and $6 \%$ of Alnus glutinosa. In addition to these core tree species, Acer platanoides, Sorbus aucuparia and Populus nigra also figured in the list of host plants with only one record. In Poland, the distribution of species (probably O. barnabita) was not random with respect to tree 
species (Oleksa 2007). Contrary to common belief, the hermit beetles of Poland did not prefer oaks, avoided Acer platanoides and Carpinus betulus and preferred Tilia cordata and Alnus glutinosa. Furthermore, they showed a significant predilection for trees of about $450 \mathrm{~cm}$ in circumference at $1.3 \mathrm{~m}$ height and did not show any dependence on the hollow entrance area and exposition (Oleksa 2007). A habitat study in central Italy (Chiari et al. 2012), conducted by wood mould sampling in 151 hollow trees belonging to eight broadleaf species, revealed that O. eremita was present in $22 \%$ of the trees, all belonging to four species, Ostrya carpinifolia (60\%), Quercus suber (25\%), Acer obtusatum (6.6\%) and Quercus pubescens (1\%). The number of larvae and remains was higher in cavities with more than 4 litres of wood debris, where the wood mould was relatively dry and had low soil contamination. Successful colonisation and breeding of the hermit beetle was obtained in an artificial habitat i.e. wooden boxes filled with oak leaves and sawdust, placed in natural conditions in Sweden and Poland (Jansson et al. 2009, Hilszczański et al. 2014, Carlsson et al. 2016).

Despite being able to fly, hermit beetles show a low dispersion distance. In Sweden, O. eremita showed a limited dispersal rate and mean dispersal distances of less than $200 \mathrm{~m}$, with only $15 \%$ of the adults leaving their natal hollow tree (Ranius and Hedin 2001, Hedin and Ranius 2002, Ranius 2006, Hedin et al. 2008, Svensson et al. 2011). In France, Dubois and Vignon (2008) reported for one individual of O. eremita a total dispersal of $700 \mathrm{~m}$. The dispersal patterns of $O$. eremita were studied in a cork oak (Quercus suber) woodland in central Italy, the southernmost part of its distribution range which was characterised by a hot and dry Mediterranean climate (Chiari et al. 2013b). The dispersal activity of 39 individuals (16 males, 23 females) was followed by a 2 -year radio-telemetric approach and the results showed that hermit beetles spent their lifetime not only inside hollow trees but also in other habitats, such as under the ground surface. The beetles were more active at the beginning of the season but $81 \%$ of males and $69 \%$ of females continued to disperse during their lifetime. The dispersal distance over their lifetime did not differ between sexes and the longest dispersal was performed by a female that travelled $1,504 \mathrm{~m}$, while $39 \%$ per cent of dispersing individuals reached distances further than $250 \mathrm{~m}$. Both the dispersal rate and range are higher than that which has been found in northern and central Europe. The population size per tree is low, most of the adults leaving their natal tree and a high predation rate (at least 28\%) was observed (Chiari et al. 2013b).

Tethered flight experiments were conducted in the laboratory by Dubois et al. (2010) where a flight mill was used to measure the flying activity for each individual. These experiments revealed a maximum single flight distance of $1,454 \mathrm{~m}$ and a maximum total flight distance of $2,361 \mathrm{~m}$, also demonstrating a higher flight capacity in females than males. Investigations on the factors that may affect flying activity, e.g. temperature, humidity or feeding on fresh fruit as sources of energy such as plums (which are rare or absent in forest ecosystems), should be carried out for assessing the potential flight capacity of the species.

As the daily activity of hermit beetles varies according to light, temperature and humidity, they have been recorded as active both day and night by different studies. In 
Sweden, during a long term research project, the adults were only found active at daytime, with flying individuals mainly seen in the early afternoon on warm, sunny days (Ranius 2005); on the contrary, in central-southern European countries (Germany and France), they have been observed to be active at dawn (Stegner 2002, Schaffrath 2003a). In central Italy, a telemetric study showed that hermit beetles are active both day and night, over a span of 24 hours (Chiari et al. 2013b). In Valtellina (north Italy, ca $500 \mathrm{~m}$ asl) the patrolling activity of males outside the hollows was mostly observed from $1400 \mathrm{~h}$ to $1900 \mathrm{~h}$ and flying specimens (both males and females) were also observed in the early afternoon of July and August in warm, sunny days, as in Sweden (P. Audisio, unpublished data). All these phenological data seem to suggest that the daily activity can shift towards the hours when the beetles find the most favourable climatic conditions, e.g. preferring the day-time in cool and humid areas but night-time in warm and dry ones.

\section{Threats and conservation measures}

Hermit beetles represent one of the most important "flagship" species and "umbrella" species for the protection of the local saproxylic communities (Ranius 2002a, 2002b, 2002c, Audisio et al. 2003, Carpaneto et al. 2015). In 1992, O. eremita was listed as a priority species in Annex II and IV of the EU's Habitats Directive (Luce 1996, 2001, Galante and Verdú 2000, Audisio et al. 2003, Ranius et al. 2005), when the systematic knowledge of the group was still very poor. Until the present time, the only Osmoderma species formally protected by the Habitats Directive is $O$. eremita, even though the need for conservation of all related taxa derived from its splitting was expressed by several authors and is provided by the Directive itself (Audisio et al. 2008, 2009, 2014, Carpaneto et al. 2015).

The conservation status and threats of the European hermit beetle species have been assessed for the IUCN Red List: O. eremita (Nieto et al. 2010), O. cristinae (Nardi and Micó 2010), O. barnabita (Alexander et al. 2010). An overview of the opinions, expressed by several authors, has led to the recognition of the following threats, listed in order of importance:

1. Decreasing number of hollow veteran trees (habitat trees) in forest ecosystems due to commercial management which was not suitable for the conservation of biological diversity;

2. Fragmentation of old-growth forests and lack of connection amongst the habitat trees;

3. Felling of chestnut orchards or their transformation to coppices;

4. Transformation or felling of ancient orchards with old fruit trees of the rose family (especially Prunus);

5. Abandonment of pollarding practices on willows, poplars, mulberry trees and other species across the rural landscape; 
6. Removal of dead wood and old trees from forests or hedgerows for civic use such as domestic fuel;

7. Increasing use of old trees and dead wood in general as biomass for industrial fuel production;

8. The lack of entomologists involved in risk management assessment of dangerous old trees in urban parks and country roads for ensuring both human safety and biodiversity conservation;

9. Risk of pheromone use by insect dealers for international trade of rare species.

The long-term research conducted in Sweden, where hermit beetles live aggregated into large hollow oaks within small tree stands, concluded that there is a considerable extinction risk for many populations as they mainly rely on only one or a few trees with large amounts of wood mould and $10 \%$ of the hollow trees harbour two thirds of the individuals (Ranius 2007, Ranius et al. 2009). According to Vignon (2015), many chestnut groves in France have not been renewed since the late $19^{\text {th }}$ century and the habitat transformation from chestnut orchards to coppices represents the following serious threats for hermit beetles: (1) loss of a suitable habitat, (2) barriers for dispersal because the species is not able to fly in dense coppices and (3) colder climatic conditions for a species whose development is favoured by the sun heating the trees. According to Dubois and Vignon (2015), hermit beetles are damaged by dense woodlands, mainly coppices, as they are unable to avoid twigs and fall to the ground thereby risking reproductive failure. Indeed, remarkable aggregations of hermit beetles have been observed in French orchards, especially on apple trees and in open parts of the agricultural landscape where they preferred pollarded oaks of hedgerows (Dubois et al. 2009). According to Oleksa et al. (2007), hermit beetles do not require old-growth forests to survive whereas, on the contrary, they seem to avoid forests with a dense canopy. Open woodlands or densely wooded pastures with old hollow trees, seem to be the optimum habitat type for these beetles, provided that renewal of trees is ensured over the years to balance veteran tree death. As a matter of fact, hermit beetles occupy anthropogenic habitats whenever suitable trees are present. These facts and other findings suggest that hollow veteran trees in ecotones as forest edge, along country roads or channels might play a crucial role in the preservation of this species, while changes in traditional structures of agricultural landscapes (e.g. the cutting down of old hedgerow trees) could result in a rapid extinction of the species at the local level. Further studies are needed to investigate the occurrence of hermit beetles in different types of habitats to judge how far the species is connected with anthropogenic habitats or whether such environments play only a secondary role. The protection of hermit beetles requires the preservation of sites with a network of suitable trees in space and time where natural forests and rural habitats occur together and any preservation strategy must plan the balancing of long-term processes for cavity creation and disappearance in order that suitable cavities are always present. Tree management for saproxylic conservation should bear in mind that the creation of a new cavity can take several tens to hundreds of years in trees with harder wood, such as oak or beech, but this process is very much faster in softer 
wood, such as that of limes, alders, poplars or willows. Only a few oaks and beeches, younger than 150 years, develop large hollows suitable for hermit beetles (Nilsson et al. 2001) while limes of only 70 years have been observed to possess cavities occupied by these beetles (Oleksa et al. 2007). The low dispersal ability of hermit beetles and their preference for open woodlands seem to be the major causes for the sensitivity of these animals to tree management and vulnerability to habitat alteration (Ranius and Hedin 2001, Dubois 2009, Dubois et al. 2009). Artificial cavities, i.e. boxes full of wood mould, can be a useful strategy for filling gaps in time and space and making a fragmented landscape more suitable for O. eremita (Jansson et al. 2009).

\section{Review of monitoring experience in European countries}

Until the present time, several methods have been used to study and monitor the $O$. eremita populations, mainly based on: (1) searching or capturing the adults by either pitfall and pheromone traps or visual survey and (2) wood mould sampling, searching for the remains of adults and frass or larvae in hollow trees. These methods are however often used in combination to achieve a greater sampling efficacy. In the following paragraphs, an overview is presented of the monitoring methods used for the different European countries on the genus Osmoderma.

\section{Sweden}

In this country, the standard method for the monitoring of $O$. eremita populations was developed by using traditional methods, like pitfall trapping and/or wood mould sampling (Ranius and Nilsson 1997, Ranius 2000, 2001, Ranius and Jansson 2002), as well as more innovative pheromone-based approaches (Larsson et al. 2003, Svensson et al. 2003, Larsson and Svensson 2009).

Ranius and Nilsson (1997) tested wood mould sampling on 135 trees for three years. Every year, the sampling was undertaken in September. From each hollow, tree samples of wood mould between 2-8 litres were extracted and carefully examined for larvae, fragments and frass. In order to obtain information on population size, Ranius (2000) suggested the use of the pitfall traps inside hollow trees, with the entrance hole wide enough, $<5 \mathrm{~m}$ from the ground and the wood mould surface not too far from the entrance hole. The traps were empty jars with a top diameter of $7 \mathrm{~cm}$, positioned with the openings at a level with the wood mould surface. The traps needed to be checked every day or every two days and hermit beetles searched for in the hollows and on trunks in order to increase the probability of detecting the species (Ranius 2000, 2001). Each beetle was marked on the elytra with an insect needle in a drill. The optimum monitoring period was from the 2 nd or 3rd week of July until the end of August (Ranius 2001). Furthermore, Ranius (2000) and Ranius and Jansson (2002) suggested carrying out the wood mould sampling before the survey with pitfall traps in order to set the traps in tree hollows where fragments have been found. The occurrence of fragments is an accurate indicator of the presence of the species, since there is a strong 
correlation between occurrence of fragments and of living adults and frass from larvae in hollow oaks (Ranius and Nilsson 1997). However, the above- mentioned methods were considered labour intensive and time consuming (Svensson et al. 2012) and can be applied only for trees with certain characteristics.

The identification of the peach-like, fruity odour of the hermit beetles as $(R)-(+)-\gamma-$ decalactone and the identification of its function as a sex pheromone released by males to attract females, allowed the development of different methods useful for monitoring the species. Svensson et al. (2003) used the air sampling method. The air was sampled from the cavity by using Micro Diaphram Gas Sampling Pumps connected to a charcoal filter and extracts analysed using gas chromatography and mass spectrometry. However, this method is limited in that females cannot be detected and the mainly problematic aspect is the need for costly equipment (Svensson et al. 2003). The air sampling method can however be a useful complement to other methods when trying to detect as many trees housing this beetle as possible.

Svensson and Larsson (2008) for the first time tested the "custom built trap", also called the pheromone trap, baited with the pheromone of the species. They positioned 12-20 replicates of traps for three years. The traps were suspended from tree branches at $2-4 \mathrm{~m}$ height and at least $10 \mathrm{~m}$ apart. The traps would be checked every second day. They suggested undertaking the monitoring from the end of June until the end of August (Svensson and Larsson 2008). Pheromone traps outside trees and pitfall traps inside tree hollows, facilitate the mark-recapture of beetles (Larsson and Svensson 2009, Svensson et al. 2011) and the estimation of both population size and dispersal rate of the species (Ranius 2001, Ranius and Hedin 2001, Hedin et al. 2008, Svensson et al. 2011).

Furthermore, in 2016, a national monitoring programme was carried out in 73 sites, from 19 July until 1 August using 198 pheromone traps and 114 pitfall traps. The traps were checked every three days. During the sampling, 56 hermit beetles from 43 pheromone traps and 29 beetles from 12 pitfall traps were detected respectively $(\mathrm{N}$. Janssons, pers. com.).

\section{Finland}

In 2012, in order to achieve a comprehensive assessment of the national distribution of $O$. barnabita, a pheromone-based plan was designed and implemented by volunteers in several urban parks and in all major oak woodlands in Finland (Landvik et al. 2015). The volunteers were amateur and professional entomologists, contacted by advertisement; the protocol and the sampling set (trap, bait etc.) were supplied by the project. The sampling was carried out from 2012 until 2014 in 52 sites, during the flight activity of the species from mid July to mid August, using 2-4 traps per site. Despite the massive sampling effort of more than 3,500 trap-days, O. barnabita was only detected in the Ruissalo Island (SW Finland). The presence of O. barnabita at the level of host trees was evaluated by a standardised method: the site was divided into squares of 250 x $250 \mathrm{~m}$ and, in each square, the hollow trees were detected and analysed by sieving the wood mould from any remains of adults, frass and larvae of the species (Landvik et 
al. 2015). Signs of hermit beetles were detected in 62 trees out of 192 total examined (32\%) and the most preferred host was pedunculate oak (Quercus robur), with additional occurrences in lime (Tilia) and alder (Alnus). Large trees were more frequently occupied than smaller ones, with an incidence of $90 \%$ on the largest oaks.

\section{Norway}

During the last 100 years, live specimens of the O. eremita had not been found in Norway and the species was presumed regionally extinct (category "Extinct?") (Ranius et al. 2005 and reference therein, Kalas et al. 2006). Surprisingly, during the summer 2008, the species was detected in the cemetery of Tonsberg, in the county of Vestfonl (Flaten and Fjellberg 2008). The monitoring project of hermit populations was carried out using different methods. In July 2008, four adults were detected by using visual encounter surveys while 14 larvae of third stage and frass were found inside the hollow trees by wood mould sampling. During August 2009, "sweep cameras", set inside hollow trees, were added to other methods (SverdrupThygeson et al. 2010). While in 2010, the hermit beetles were monitored by using the sweep camera and pheromone traps and marked with labels. Sverdrup-Thygeson et al. (2010) recommended the development of a strategy to care for and conserve the veteran trees where the beetle population currently lived. Efforts are also necessary to establish new host trees for future generations by using artificial hollow trees. Hermit populations should be monitored annually to follow population trends, using both a visual search for adults in hot summer evenings during their mating season and a special "sweep camera" to see inside tree cavities (Sverdrup-Thygeson et al. 2010). Furthermore, the action plan provides some activities in order to familiarise the citizens with the species.

\section{Poland}

Despite the large number of occurence sites of hermit beetles in Poland (see Oleksa 2009) and several studies carried out (Oleksa and Gawronski 2006, Oleksa et al. 2006, 2007, 2012, Byk et al. 2013, Hilszczanski et al. 2014), a national monitoring protocol on hermit beetle populations has still not been proposed. Oleska (2009) suggested measures for conservation focused not only on veteran trees in open areas, along avenues or channels and in old-growth forests, but also on the entire landscape inhabited by populations of hermit beetles in Poland. Therefore, an action plan for the species (locally represented only by $O$. barnabita) should include three steps: (1) localisation of core areas using both target species and structure-based indicators, such as the presence of old trees; (2) strict protection of corridors in fragmented landscapes (trees in roadsides and canal banks), including management to keep some areas open, e.g. by grazing or cutting and (3) restoration of stepping stones between core areas, planting trees in places where the continuity of habitat has been disturbed, as well as other measures enhancing the hollow continuity in space and time e.g. promoting hollow creation by pollarding trees or fungal inoculation. 


\section{Germany}

In southern Germany, where both O. eremita and O. barnabita are known to occur, the monitoring method proposed is the wood mould sampling by using the "vacuum cleaner method", used for the first time by Bußler and Müller (2008). A suction tube of a vacuum cleaner (Nilfisk Backuum battery) was introduced into the cavity, extracting each time 3.5 litres of wood mould. The sample was checked for frass, pellets, adults, larvae and remains of the hermit beetles. Sampling was undertaken on 127 tree cavities during 2006 and 2007, in eight Nature 2000 areas in southern and northern Bavaria. Hermit beetles were recorded in 39 tree cavities. In particular, larvae were recorded in 11 trees and remains in 30 samples. This method allows good results to be obtained but has a significant impact on the microhabitat structure and negatively affects the saproxylic communities.

\section{France}

In France, several monitoring programmes for hermit beetle populations were undertaken by using different methods separately and in combination: wood mould sampling (Vignon and Orabi 2003, Vignon et al. 2004, Dubois et al. 2009); pitfall traps and telemetry (Dubois and Vignon 2008); wood mould sampling, pitfall traps (Vignon 2008) and telemetry (Dubois and Vignon 2008, Vignon 2015, Le Gouar et al. 2015). In all studies, the authors suggested the creation of an inventory of suitable hollow trees by mapping them by GPS and recording the features of the trees (see Ranius 2001). The rate of occupancy of the species was detected by using the wood mould sampling method, searching for the larval faecal pellets, larval stages, cocoons and adult body parts inside the cavities. This method was mainly applied during the winter (Dubois and Vignon 2008). Furthermore, the authors suggested the capture of adults using pitfall traps set in the cavities, one or two for each tree, checked at least every two days and most frequently once a day. In Dubois and Vignon (2008) and Le Gouar (2015), the traps were visited once per day, five days per week from the beginning of July until the end of August, when the daily total number of captures fell below one capture per day (Le Gouar et al. 2015). In order to estimate the size of populations, the capture-recapture method was applied by marking the individuals with micro-perforations made in elytra with a thin drill, with a combination of six perforations. Furthermore, adults were also searched for on wood-mould surfaces or at the entry to the cavity and on trunks during the routine time of visits to the traps. In the recent work published by Vignon (2015), the results are reported of the long term monitoring studies conducted for 16 years (1997-2013) in the Sarthe department in chestnut (Castanea sativa) orchards and for 7 years (2001-2008) in the Orne department in hedgerow networks. The surveys were carried out using pitfall traps and radio telemetry for 950 days with 14 persons capturing 612 individuals. The most relevant result was that the adults emerged from the end of June until the end of August with an emergence peak between 10 and 15 July; a second emergence peak was observed between 25 and 29 July. 


\section{Romania}

In Romania, the standard method for the monitoring of Osmoderma (locally represented only by O. barnabita sensu Audisio et al. 2007, 2008) is based on a combination of methods and spread temporally throughout the seasons in order to monitor the species in the best manner (Iorgu et al. 2015). The occurrence of the species was established by wood mould sampling and the materials in the hollow trees were sieved out on to a white sheet of $1 \mathrm{~m}^{2}$, to search for frass, adults, remnants and larvae. Iorgu et al. (2015) established the screening of the hollow trees on a standard area of 1 ha (e.g. a transect $500 \mathrm{~m}$ long and $20 \mathrm{~m}$ wide). Suitable trees were geo-referenced by using a GPS. The time spent for searching in the standard area was almost 2 hours with two operators. The populations of hermit beetle can be monitored by using the pheromone traps with $\gamma$-decalactone. The monitoring should be carried out to find larvae throughout the seasons and to find the adults between July and August (Iorgu et al. 2015).

\section{Austria}

In Austria, the monitoring protocol on hermit beetle populations has still not been proposed, although $O$. eremita was considered a highly endangered species from past knowledge and the species was thought to have become extinct due to habitat loss (Ranius et al. 2005). In the northeastern part of Lower Austria, from 2008 to 2011, the occurrence of $O$. eremita (s.l.) was studied by using wood mould sampling, searching for frass, adults, remnants and larvae in the cavities (Straka 2009, 2011). This method was applied without destroying the microhabitat of the species. Fifteen new occurrence sites were found, mainly in relicts of the historical cultural landscape, such as castle parks, avenues with pollarded trees and only one population was found in natural oak wood. The species was recorded in 49 old trees (sometimes $>200$ years old), frequently in lime (Tilia cordata) and willows (Salix alba, Salix fragilis, S. $x$ rubens) and rarely in black popular (Populus nigra), pedunculate oak (Quercus robur) and appletree (Malus domestica) with diameters ranging from 45 to $260 \mathrm{~cm}$. The surveys were carried out during the whole year.

\section{Switzerland}

In 2004, a management plan for old trees was developed to protect saproxylic beetles in urban and periurban areas (Juillerat and Vögeli 2004). The main aim of the plan was to maintain and to improve the sites for an extended period in order to protect the species, evaluating suitable measures of forest management. The action plan suggested combined monitoring for each tree of relict and urban forests, for all the saproxylic beetles. The plan recommended citizen participation to improve the knowledge on the distribution of the species. The monitoring of $O$. eremita was carried out by searching for presence signs within the cavities of the wood mould. The samples of mould were sieved to isolate frass produced by larvae $(>7 \mathrm{~mm})$, larval stages and remnants of adults; the dark brown droppings and many large fragments $(>10 \mathrm{~mm})$ attested to the recent 
presence of the species. The plan suggested the best time to undertake this research was from July to October (Juillerat and Vögeli 2004).

\section{Slovenia}

In this country, the monitoring method for O. eremita (s.l.) populations was published for the first time by Vrezec et al. (2014). The surveys were carried out by using baited traps with a racemic mixture of pheromone. Each selected site was monitored using different numbers of traps, between 1 and 199, for about two weeks depending on the workers involved for each area and the characteristics of the study site. However, Vrezec et al. (2014) suggested to use 20 traps for each site and to check the traps once a week. The monitoring should be carried out during July which is considered the activity period of the species in Slovenia (Vrezec 2008).

\section{Italy}

In Italy, Campanaro et al. (2011) proposed the first method for the monitoring of $O$. eremita based on the capture-mark-recapture procedure. The authors suggested capturing individuals mainly by using the pitfall traps (PT: i.e. empty jars placed inside the cavity of hollow trees) as it resulted in efficient capture of adults and also because it was the cheapest method and traps could more easily be constructed; moreover, they suggested the use of black cross window traps (BCWT: i.e. two black plastic sheets attached to a plastic funnel leading down to a plastic bottle, baited with a racemic mixture of $\gamma$-decalactone, placed on the trunk and suspended from tree branches) mainly in woods without hollow trees and during preliminary investigations; finally, they suggested the avoidance of interception air traps (IAT: i.e. a transparent plastic shield with a plastic dust-funnel leading down to a plastic bottle baited with a racemic mixture of $\gamma$-decalactone, placed on the trunk and suspended from tree branches) as it was less efficient in capturing adults of O. eremita. Chiari et al. (2013a) found a similar result by comparing four independent capture methods for the monitoring of O. eremita in central Italy: BCWT, PT, IAT and VES, visual encounter surveys (i.e. searching adults by visual inspection of hollows and trunks). Indeed, the PT appeared the best method in terms of high detection probability, low cost and least time for construction, low sensitivity to damage and less time for checking and restarting in the field (Chiari et al. 2013a). Regarding the BCWT, Zauli et al. (2014), by using these traps as a capture method for monitoring adults of O. eremita in Central Italy, could draw attention to two populations of this species reduced to a minimum number of individuals and exposed to local extinction. As well as for the other European species belonging to the genus Osmoderma, the BCWT baited with a racemic mixture of $\gamma$-decalactone attracted (also for O. cristinae) an endemic species of Sicily, in south Italy, suggesting that these types of traps can also be used for the monitoring of this species (Zauli et al. 2016a). A further method, the wood mould sampling, performed by Chiari et al. (2012) in central Italy, was used to detect presence/absence of $O$. eremita (larvae, frass and remains of dead individuals) by examining wood mould samples taken from the tree cavities. 
Regarding the setting of the traps in sampling areas, Campanaro et al. (2011) proposed the arrangement of the PT and BCWT along linear transects, at the nodes of a grid (in both cases at a distance between 30 and $50 \mathrm{~m}$ ) or alternatively, in a random manner. Chiari et al. (2013a) used the random manner, setting the traps on 116 hollow trees randomly selected. Regarding timing of sampling, both groups of researchers indicated that the monitoring of $O$. eremita should be undertaken during the peak of its activity, i.e. from the middle of June until the middle of August, respectively, at sea level in northern Italy (Campanaro et al. 2011) or at a hilly area in Central Italy (Chiari et al. 2013a). Campanaro et al. (2011) also suggested undertaking a minimum of six monitoring sessions. Trizzino et al. (2013) and Bologna et al. (2016) shared the suggestion for the monitoring method of O. eremita proposed by Campanaro et al. (2011) and Chiari et al. (2013a).

\section{Methods}

Three methods were selected at the beginning of the project (for details on the project, see Mason et al. 2015 and Carpaneto et al. 2017), for testing over a period of three years (from 2014 to 2016) in two macroareas: the Foreste Casentinesi (hereafter: FC) and the Parco Nazionale d'Abruzzo Lazio e Molise (hereafter: PA). Two methods, pheromone and pitfall traps which were tested during the project, are described below while the detailed description of the third method, the use of a trained dog, is reported in this issue with Mosconi et al. (2017).

A preparatory phase was conducted to select the sites and the period for monitoring of hermit beetle populations. Firstly, an analysis of previous data from literature and the study of collections of museums and private owners were carried out for an overview of the presence of the species and its phenology. Moreover, preparatory surveys were made during autumn-winter 2013-2014 in order to select the best suited sites in the two macroareas (FC and PA) for setting traps in the coming years (considering accessibility, presence of the species, forest structure etc.). During these surveys all potential suitable trees were mapped by GPS and the main features were recorded to create an inventory.

\section{Pheromone Traps}

Black cross window traps (hereafter: BCWT) were used, functioning as interception air traps baited with the pheromone produced by males of O. eremita (Svensson and Larsson 2008, Chiari et al. 2013a). They consisted of two black plastic sheets $(25 \mathrm{~cm}$ height $\mathrm{x} 30 \mathrm{~cm}$ width, $3 \mathrm{~mm}$ thickness), arranged in a cross and attached perpendicularly to a white plastic funnel (upper diameter $30 \mathrm{~cm}$, neck diameter $4 \mathrm{~cm}$ ) leading down to a 0.5 litres white plastic bottle (Figure 7). Traps were set on tree branches at a height of $2-4 \mathrm{~m}$ (Figure 7B). 


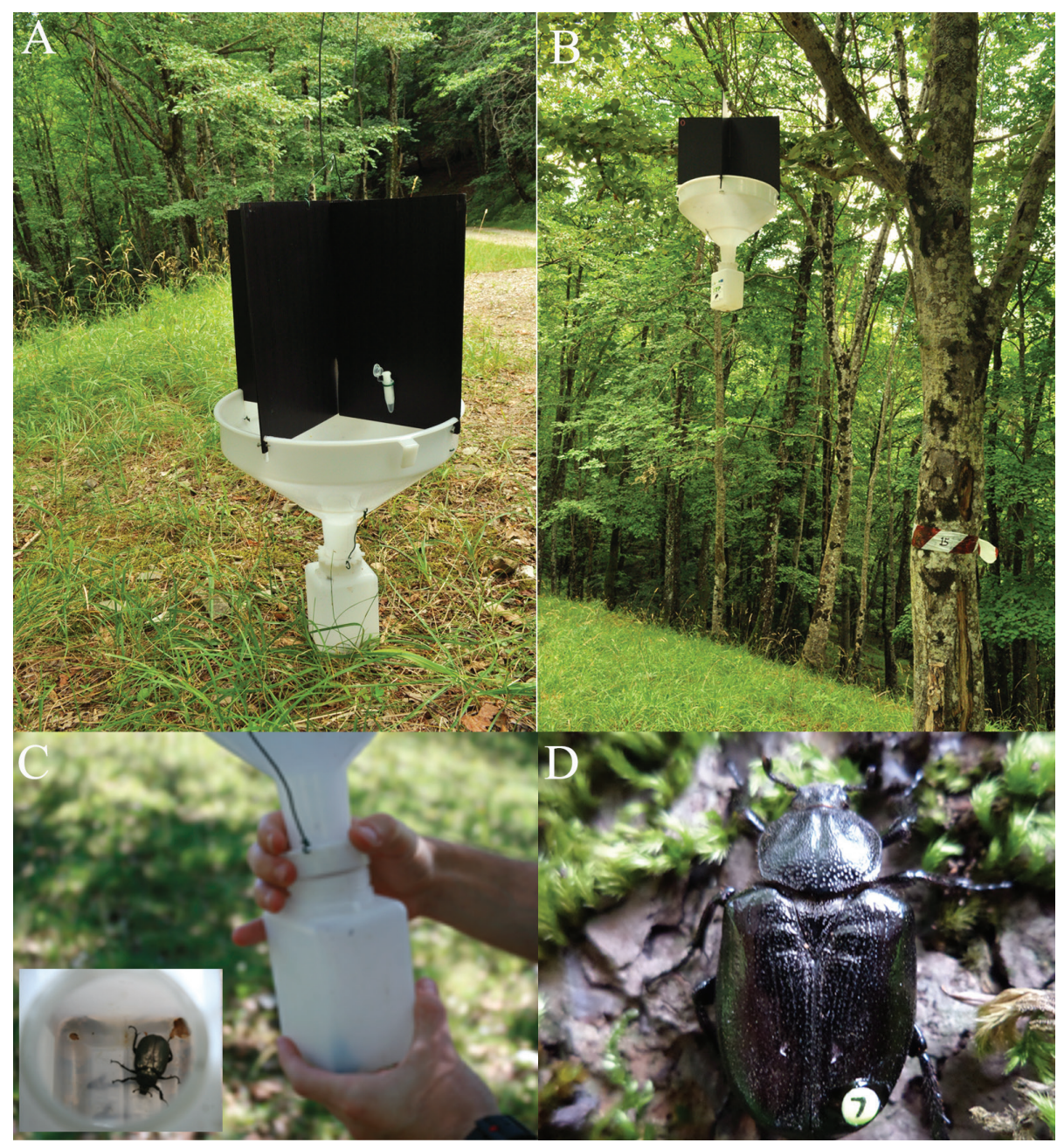

Figure 7. BCWT for capturing O. eremita. A Outline of a trap with an eppendorf vial containing the pheromone $\mathbf{B}$ positioning on tree branch $\mathbf{C}$ insertion of the funnel into the bottle, with details of hermit beetle captured by the trap (note the four small holes in the base to avoid water filling) D O. eremita with double marking procedure on elytra: dimples made by a small drill and a numbered sticker (photographs by E. Capogna: A-B, F. Bernardini: C, S. Chiari: D).

Dispensers for pheromone were $1.5 \mathrm{ml}$ plastic eppendorf vials loaded with $1200 \mu \mathrm{l}$ of the racemic mixture of $\gamma$-decalactone (catalogue no. W236004, Sigma-Aldrich, USA). Cut strings of cotton dental rolls (Celluron, Paul Hartmann, S.A., France) were inserted as wicks into the dispenser. The dispensers were attached to the traps with a metal hook (Figure 7A). Traps were checked every second day to avoid the death of beetles inside the bottle. Moreover, the plastic bottles were equipped with several small holes at the base to avoid water filling by rainfall and possible death of the beetles (Figure 7C). The traps were mapped by GPS (Garmin 60Csx) and then marked by a label with information on the Project and the code of the trap. 


\section{Pitfall Traps}

Pitfall traps (hereafter: PT) were used to catch beetles walking on the wood mould surface inside the cavities. PT consisted of empty jars, with an opening diameter of around $7 \mathrm{~cm}$, placed inside the wood mould with the opening at the surface of the mould (for details see Campanaro et al. 2014, Chiari et al. 2013b). PT, mapped by using GPS and marked by a label with the code of the trap, were checked every second day.

\section{Capture release method}

At the first capture, the sex of each hermit beetle was determined by examining head and pronotum morphology. Afterwards, each beetle was marked on the elytra by a numeric code following a double procedure (Figure 7D): 1) by a small drill (Dremel Lithium Cordless 8000JE) and 2) applying a numbered sticker by a very small drop of cyanoacrylate glue ('Loctite, Super Attack Power Flex Gel; Henkel, Dusseldorf, Germany). No beetle was damaged by the marking procedure.

\section{Sampling plan}

Within the macroarea FC, trap sampling was undertaken in two sites: Foresta della Lama (FL) and Camaldoli (CA) which were dominated by beech and chestnut respectively. Within the macroarea PA, traps were set in three study sites: Difesa di Pescasseroli (DP), Val Fondillo (VF) and the Riserva Naturale Feudo Intramonti e Colle di Licco (FI). The first two areas were dominated by beech forests and the third area was occupied by oak forests (for other information on the study areas, see Carpaneto et al. 2017).

In 2014, trapping was only undertaken in the macroarea PA (in two sites, DP and VF), during July (Table 1) by using 15 replicates of three BCWT. Each replicate was set at least $100 \mathrm{~m}$ from each other and contained: a single trap baited with two eppendorf vials with $600 \mu \mathrm{l}$ of $(\mathrm{R})$-enantiomer; a single trap baited with one eppendorf vial with $1200 \mu \mathrm{l}$ of racemic mixture and one empty trap (without pheromone) as control. Inside each replicate, traps were hung on tree branches at $2-4 \mathrm{~m}$ height, at least $10 \mathrm{~m}$ apart and they were checked for the presence of beetles every second day, for 5 surveys in total. The relative position of traps within each replicate was changed every two days.

These field experiments addressed the following questions: (i) are the sites suitable for the species? (ii) what is the most efficient marking technique for hermit beetle populations? (iii) does the use of $1200 \mu$ lin one or two dispensers affect the efficacy of the method? (iv) is the method suitable for detecting the species and estimating relative abundance?

In 2015, trapping was conducted in both macroareas: PA (in three sites DP, VF and FI) and FC (in two sites, FL and CA). For each site, 10 BCWT and 10 PT were 
Table I. Sampling design used during the MIPP project. Summary of the sampling design followed during the study of $O$. eremita in three years. $(\mathrm{PA}=$ Parco Nazionale d'Abruzzo Lazio e Molise; FC= Foreste Casentinesi; VF = Val Fondillo; DP = Difesa di Pescasseroli; FI= Feudo Intramonti e Colle di Licco; CA= Camaldoli; FL = Foresta della Lama).

\begin{tabular}{lccccc}
\hline Macroarea & Site & \multicolumn{2}{c}{ Method } & Study period & \# Survey \\
\hline \multirow{2}{*}{ PA } & VF & 45 BCWT & - & $21 / 07-31 / 07 / 2014$ & 5 \\
& DP & 45 BCWT & - & $21 / 07-31 / 07 / 2014$ & 5 \\
\multirow{2}{*}{ PA } & VF & 10 BCWT & $10 \mathrm{PT}$ & $15 / 07-28 / 08 / 2015$ & 21 \\
& DP & $10 \mathrm{BCWT}$ & $10 \mathrm{PT}$ & $15 / 07-28 / 08 / 2015$ & 21 \\
& FI & $10 \mathrm{BCWT}$ & $10 \mathrm{PT}$ & $15 / 07-28 / 08 / 2015$ & 21 \\
FC & CA & $10 \mathrm{BCWT}$ & $10 \mathrm{PT}$ & $15 / 07-18 / 08 / 2015$ & 14 \\
PA & FL & $10 \mathrm{BCWT}$ & $10 \mathrm{PT}$ & $15 / 07-18 / 08 / 2015$ & 14 \\
FC & DP & $10 \mathrm{BCWT}$ & $10 \mathrm{PT}$ & $18 / 07-12 / 08 / 2016$ & 12 \\
\hline & FL & $10 \mathrm{BCWT}$ & $10 \mathrm{PT}$ & $18 / 07-12 / 08 / 2016$ & 12 \\
\end{tabular}

used. BCWT were positioned on tree branches at $2-4 \mathrm{~m}$ height and baited with one eppendorf vial containing $1200 \mu \mathrm{l}$ of racemic mixture. PT were positioned inside the tree hollows amongst suitable trees which had previously been investigated in 2014 . The distance between BCWT and PT was at least $100 \mathrm{~m}$. Traps were checked for the presence of beetles every second day, three times a week (Table 1). Four site covariates were recorded for each site in 10 plots of $24 \mathrm{~m}$ radius $\left(\right.$ Area $=1808 \mathrm{~m}^{2}$ ) (Redolfi De Zan et al. $2014 \mathrm{a}, \mathrm{b}$ ) around the tree where the BCWT were set: (1) trees number (TN); (2) mean circumference (MC); (3) holes number (HN) and (4) microhabitat amount (MA). Starting from the habitat suitable for O. eremita, the number of trees (old trees with hollows) with a circumference greater than or equal to $157 \mathrm{~cm}$ at breast height $(\mathrm{DBH})$ was recorded in the area. For each tree, the number of cavities and the number of "microhabitat type" identified were also recorded. Following Winter and Möller (2008), "microhabitat type" was used as a method with which it is possible to obtain information on the structure of the forest investigated and also to correlate the presence of microhabitat data with the presence of saproxylic species. Amongst the 20 microhabitat types identified, according to the scheme proposed by Winter and Möller (2008), only those most suitable for the presence of $O$. eremita were taken into account from MA04 to MA10 (see Winter and Möller 2008).

These field experiments addressed the following questions: (i) between BCWT and PT, what is the better method to detect hermit beetles? (ii) is the colour numbered sticker a reliable method to mark hermit beetles? (iii) what is the lower limit of population abundance for using the capture-release method? (iv) what is the minimum sampling effort (in terms of trap and survey number) for detecting the species? (v) do environmental variables of the plot have a relationship with the species occurrence?

In 2016, trapping was again conducted in both macroareas: PA (in two sites DP and VF) and in FC (in one site FL). For each site, 10 BCWT and 10 PT were used. 
The BCWT were positioned on tree branches at $2-4 \mathrm{~m}$ height and baited with one eppendorf vial containing $1200 \mu \mathrm{l}$ of racemic mixture. PT were positioned inside the tree hollows, previously selected amongst suitable trees investigated in 2014. The distance between BCWT and PT was at least $100 \mathrm{~m}$. Traps were checked for the presence of beetles every second day, for three times a week for a total of 12 surveys (Table1). These field experiments addressed the following questions: (i) what is the best method to detect hermit beetles? (ii) is the colour numbered sticker a reliable method to mark hermit beetles? (iii) what is the population abundance by using capture-release method?

\section{Statistical analysis}

For the dataset of 2014, the Yates corrected $\chi^{2}$ test was applied to investigate differences between male and female captures. Analysis was performed with the programme $\mathrm{R}$ version 3.2.5 ( $\mathrm{R}$ Core Team, 2016), using a significance level of 0.05 to reject the null hypothesis.

The large-scale occupancy probability $(\psi)$ was firstly explored by condensing detections from each capture method and fitting single species, single season and multimethod models. Then, the detection probability estimate $(\hat{p})$ was calculated applying the single species, single season and multi-method models separately to each capture method (Nichols et al. 2008). Detection probability was modelled as constant over time and detection methods $(p)$ as time-independent but different amongst methods $\left(p^{s}\right)$, as time-dependent but constant amongst methods $\left(p_{t}\right)$, or with the method as an additive effect with time $\left(p_{s+t}\right)$. Small-scale occupancy was modelled as either timeindependent $\left(\theta^{t}\right)$ or time-dependent $\left(\theta^{t}\right)$.

For the dataset of 2015, the Yates corrected $\chi^{2}$ test was used to investigate differences between sampling methods and sex. Analysis was performed as for the 2014 dataset.

Occupancy models for single species, single season were used to calculate site occupancy $(\psi)$, i.e. an estimate of the probability that a randomly selected site of the study area is occupied and the detection probability $(p)$, i.e. the probability of detecting the species by the applied monitoring method (MacKenzie et al. 2006). These parameters were modelled to be constant (.) or to vary with time ( $)$ during the first and the last survey for each study area. The recommended survey effort for monitoring schemes was calculated by applying the general advice reported by MacKenzie and Royle (2005). In particular, the simplifying assumption was applied that selected values of $\psi$ and $p$ are constant across both space and time for a standard design where all sites $(s)$ are surveyed an equal number of times $(K)$ with all surveys having the same cost. Finally, a general situation was assumed where the study is designed with a precision objective (standard error of the estimated level of occupancy) of 0.10 to determine what values of $s$ and $K$ are the most efficient to achieve the study's objective, given the assumed values of $\psi$ and $p$. The assumed values of $\psi$ and $p$ were the means obtained from the four study sites where the species turned out to be more common (DP, VF, FI, FL) and the other two sites where the species turned out to be less common, both 
from the Lazio region: Monte Soratte (F. Bernardini, unpublished master's thesis) and Forcella Buana (Chiari et al. 2013a).

Craig's model for closed populations (Craig 1953) was used to estimate the population size for each study area. The closed population model was used due to the low number of recaptures. The Coefficient Variation (CV) was calculated as the standard error divided by the number of individuals estimated and indicates the precision of the population size estimate. Population size estimates for each study area were generated with male and female data pooled together.

The species habitat relationship was analysed pooling data from all the study areas. A set of a priori models were defined with the covariates varying in a way that could explain patterns of trap occupancy. Models with single, additive and multiplicative effects of site covariates (HN, MC, TN, MA) were hypothesised.

Occupancy models, for both 2014 and 2015 data analysis, were fitted and maximum-likelihood estimates were obtained using the programme PRESENCE (Hines and MacKenzie 2004). The Akaike Information Criterion (AIC) model selection procedure was used to rank the models and model averaging AIC weights $(w)$ of candidate models $(\triangle \mathrm{AIC}<2)$ was used to obtain a weighted average of the individual parameter estimates (Burnham and Anderson 2002).

\section{Results}

In 2014, a total of 17 captures of 15 individuals and 8 captures of 8 individuals of O. eremita were made in VF and DP respectively (Table 2$)$. The female captures outnumbered male captures $\left(\chi_{1}^{2}=6.76, \mathrm{P}=0.01\right)$. Only one male and one female were recaptured, both in VF and only once.

In both sites, the estimated large-scale probability of $O$. eremita occupancy was high, but considerably uncertain (VF $\psi=0.55, \mathrm{SE}=0.18$; DP $\psi=0.80, \mathrm{SE}=0.57$ ). Model selection statistics provided strong evidence that occupancy probabilities, in both sites, were firstly influenced by the sampling method (s) (VF $w_{s}=0.98$; DP $\left.w_{\mathrm{s}}=0.96\right)$ (Table $3)$. The BCWT baited with one dispenser containing $1200 \mu \mathrm{l}$ of $\gamma$-decalactone of neat racemic mixture, performed better than those baited with two dispensers of $600 \mu \mathrm{l}$ or controls in detecting the presence of $O$. eremita in both sites (Table 4).

In 2015, in total 116 capture events of 105 individuals were registered by BCWT (Table 5). No capture events were recorded by PT. Females were significantly more abundant than males (Yates corrected $\chi^{2}=63.43$, $\mathrm{df}=1, \mathrm{P}<0.01$ ). Individuals were collected in all the study areas in a time interval between 14 July and 28 August (Figure 8).

The mean value amongst macroareas for $\psi$ was $0.98(\mathrm{SE}=0.03)$ and for $p$ it was $0.10(\mathrm{SE}=0.04)($ Table 6$)$.

For selection of a standard error for the estimated level of occupancy of 0.10 , the most efficient allocation of resources is to use 30 BCWT, each checked 23 times (690 total number of surveys).

Amongst the marked beetles, not one lost the colour-numbered sticker. 
Table 2. Dataset of mark recapture during 2014. Summary of capture-mark-recapture data of O. eremita obtained during 2014 in PA (PA = Parco Nazionale d'Abruzzo Lazio e Molise; VF = Val Fondillo; DP = Difesa di Pescasseroli).

\begin{tabular}{cccccc}
\hline \multirow{2}{*}{ Site } & Sex & Marked & control & one dispenser & two dispensers \\
\cline { 4 - 6 } & & & 0 & 3 & 2 \\
VF & male & 4 & 0 & 11 & 1 \\
& female & 11 & 0 & 1 & 0 \\
\multirow{2}{*}{ DP } & male & 1 & 0 & 4 & 3 \\
& female & 7 & & & \\
\hline
\end{tabular}

Table 3. Occupancy probabilities model selection. Summary of the model selection statistics for the study of O. eremita during 2014 in PA (PA = Parco Nazionale d'Abruzzo Lazio e Molise; VF = Val Fondillo; DP = Difesa di Pescasseroli).

\begin{tabular}{cccccc}
\hline Site & Model & $\boldsymbol{K}^{*}$ & $\mathbf{- 2 \operatorname { L o g } ( \boldsymbol { L } )}$ & $\mathbf{\Delta A I C}$ & $\boldsymbol{w}$ \\
\hline \multirow{2}{*}{ VF } & $\psi, \theta^{t}, p_{s+t}$ & 9 & 61.54 & 0.00 & 0.55 \\
& $\psi, \theta^{t}, p^{s}$ & 9 & 62.05 & 0.51 & 0.43 \\
\multirow{2}{*}{ DP } & $\psi, \theta^{t}, p_{s+t}$ & 9 & 42.99 & 0.00 & 0.52 \\
& $\psi, \theta^{t}, p^{s}$ & 9 & 43.48 & 0.49 & 0.41 \\
\hline
\end{tabular}

${ }^{*} K$ represents the number of parameters in the model and $-2 \log (L)$ is twice the negative log-likelihood value. Small sample Akaike Information Criteria (AIC) were calculated for each model. Relative AIC values ( $\triangle \mathrm{AIC}=$ the difference in AICc value relative to the top model, Burnham and Anderson 2002) and Akaike weight $(w)$, are reported for each model. Detection probabilities may vary amongst method (s) or sampling occasion ( $\mathrm{t}$ ).

Table 4. Detection probabilities estimates by monitoring during 2014. O. eremita detection probability estimates $(\hat{p})$ and associated standard errors (in parenthesis) are given for the plausible candidate models $(\triangle \mathrm{AIC}<2)(\mathrm{w}=$ Akaike's weight for each model), during 2014 in PA (PA = Parco Nazionale d'Abruzzo Lazio e Molise; VF = Val Fondillo; DP = Difesa di Pescasseroli).

\begin{tabular}{ccccccccc}
\hline Site & Model & $\mathbf{w}$ & $\hat{\boldsymbol{p}}_{\text {control }}$ & $(\mathrm{SE})$ & $\hat{\boldsymbol{p}}_{\text {one disp. }}$ & $(\mathrm{SE})$ & $\hat{\boldsymbol{p}}_{\text {two disp. }}$ & $($ SE $)$ \\
\hline \multirow{2}{*}{$\mathrm{VF}$} & $\psi, \theta^{t}, p_{s+t}$ & 0.55 & $0.00^{*}$ & $(0.00)$ & $0.34^{*}$ & $(0.16)$ & $0.10^{*}$ & $(0.08)$ \\
& $\psi, \theta^{t}, p^{s}$ & 0.43 & 0.00 & $(0.00)$ & 0.67 & $(0.27)$ & 0.20 & $(0.13)$ \\
\multirow{2}{*}{$\mathrm{DP}$} & $\psi, \theta^{t}, p_{s+t}$ & 0.52 & $0.00^{*}$ & $(0.00)$ & $0.21^{*}$ & $(0.14)$ & $0.07^{*}$ & $(0.07)$ \\
& $\psi, \theta^{t}, p^{s}$ & 0.41 & 0.00 & $(0.00)$ & 0.50 & $(0.35)$ & 0.17 & $(0.15)$ \\
\hline
\end{tabular}

* Parameter estimate reported is the mean value amongst the 5 detection probability estimates for each detection method (control $=$ BCWT with no bait; 1 disp. $=$ BCWT baited with one dispenser with $1200 \mu$ l of $\gamma$-decalactone neat racemic mixture; 2 disp. = BCWT baited with two dispensers with $600 \mu$ of $\gamma$-decalactone neat racemic mixture in each one).

The most abundant population was the one for VF $304 \pm 104$ (C.V. 0.34), the less abundant being that of FL $22 \pm 5$ (C.V. 0.23) (Table 7).

Trap occupancy was favoured by the additive effect of the hole number $\left(w_{\mathrm{HN}}=\right.$ $0.72)$ and microhabitat amount $\left(w_{\mathrm{MA}}=0.38\right)($ Table 8$)$. Increasing the $\mathrm{HN}$ and MT increased the trap occupancy (Figure 9). 


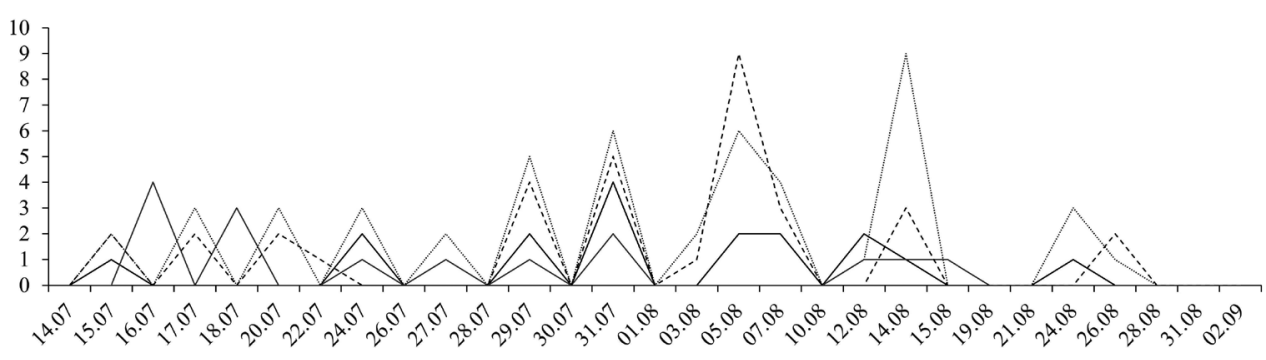

Figure 8. Time interval of capture events during 2015. Capture events of $O$. eremita during the MIPP project monitoring in 2015 in four Italian study sites (grey line = Foresta della Lama; black line = Feudo Intramonti e Colle di Licco; black dashed line = Val Fondillo; black dotted line = Difesa di Pescasseroli).

Table 5. Dataset of mark recapture during 2015. Summary of mark-recapture data obtained during the study of O. eremita in Italy with different capture methods during 2015 in the two macroareas PA and FC $(B C W T=$ Black Cross Windows Traps; PT $=$ Pitfall Traps; PA = Parco Nazionale d'Abruzzo Lazio e Molise; FC = Foreste Casentinesi $;$ VF $=$ Val Fondillo; DP = Difesa di Pescasseroli; FI = Feudo Intramonti e Colle di Licco; CA = Camaldoli; FL = Foresta della Lama).

\begin{tabular}{|c|c|c|c|c|}
\hline \multirow[b]{2}{*}{ Site } & \multicolumn{2}{|c|}{ BCWT } & \multicolumn{2}{|c|}{ PT } \\
\hline & $\begin{array}{c}\text { Marked beetles } \\
\left(+/{ }^{\lambda}\right)\end{array}$ & $\begin{array}{c}\text { Recapture events } \\
\left(\phi /{ }^{\lambda}\right)\end{array}$ & $\begin{array}{c}\text { Marked beetles } \\
\left(\left(\uparrow /{ }^{\prime}\right)\right.\end{array}$ & $\begin{array}{c}\text { Recapture events } \\
\qquad\left(+/{ }^{\prime}\right)\end{array}$ \\
\hline VF & $31 / 3$ & $2 / 0$ & $0 / 0$ & $0 / 0$ \\
\hline DP & $37 / 5$ & $6 / 0$ & $0 / 0$ & $0 / 0$ \\
\hline FI & $12 / 1$ & $4 / 0$ & $0 / 0$ & $0 / 0$ \\
\hline $\mathrm{CA}$ & $2 / 0$ & $0 / 0$ & $0 / 0$ & $0 / 0$ \\
\hline FL & $8 / 2$ & $3 / 0$ & $0 / 0$ & $0 / 0$ \\
\hline
\end{tabular}

Table 6. Occupancy and detection probability estimates by monitoring during 2015. O.eremita occupancy $(\psi)$ and detection $(p)$ probability estimates and associated standard errors (in parenthesis), are given for plausible candidate models (within $2 \triangle \mathrm{AIC}$ of the top model). The data were obtained by monitoring during 2015 in the two macroareas PA and FC (PA= Parco Nazionale d'Abruzzo Lazio e Molise; FC = Foreste Casentinesi; VF = Val Fondillo; DP = Difesa di Pescasseroli; FI = Feudo Intramonti e Colle di Licco; FL = Foresta della Lama).

\begin{tabular}{cccccccccc}
\hline Site & Model & $\boldsymbol{K}^{*}$ & $\mathbf{- 2 L o g}(\boldsymbol{L})$ & $\boldsymbol{\Delta}$ AIC & $\boldsymbol{w}$ & $\boldsymbol{\psi}$ & $\mathbf{S E}$ & $\boldsymbol{p}$ & $\mathbf{S E}$ \\
\hline VF & $\psi(),. p()$. & 2 & 167.93 & 0.00 & 1.00 & 0.93 & 0.10 & 0.15 & 0.03 \\
DP & $\psi(),. p()$. & 2 & 150.84 & 0.00 & 1.00 & 1.00 & 0.00 & 0.09 & 0.07 \\
FI & $\psi(),. p()$. & 2 & 108.07 & 0.00 & 0.99 & 1.00 & 0.00 & 0.07 & 0.02 \\
FL & $\psi(),. p()$. & 2 & 94.95 & 0.00 & 1.00 & 1.00 & 0.00 & 0.09 & 0.02 \\
\hline
\end{tabular}

${ }^{*} K$ represents the number of parameters in the model and $-2 \log (L)$ is twice the negative log-likelihood value. Relative Akaike Information Criteria $(\triangle \mathrm{AIC})$, i.e. the difference in AIC value relative to the top model modified for overdispersion (Burnham and Anderson 2002) and Akaike weight, $w$, are reported for each model. Both $\psi$ and $p$ were constant (.) within the time interval between the first and last survey of each study area.

In 2016, in total 32 captures of 31 individuals and 11 captures of 10 individuals of O. eremita were made, all by BCWT in PA and FC respectively (Table 9). No capture events were made by PT. Only two females were recaptured, one in DP and one in FL. 
Table 7. Estimation of population size. O. eremita population size estimates obtained by monitoring during 2015 in the two macroareas PA and FC (PA= Parco Nazionale d'Abruzzo Lazio e Molise; FC = Foreste Casentinesi; VF = Val Fondillo; DP = Difesa di Pescasseroli; FI = Feudo Intramonti e Colle di Licco; FL = Foresta della Lama).

\begin{tabular}{cccc}
\hline Site & Population size estimate & $\mathbf{\pm 9 5} \%$ confidence interval & Coefficient of variation \\
\hline VF & 304 & 104 & 0.34 \\
DP & 173 & 45 & 0.26 \\
FI & 22 & 5 & 0.23 \\
FL & 19 & 2 & 0.10 \\
\hline
\end{tabular}

Table 8. Dataset of environmental variables. Environmental characteristics (within $2 \triangle \mathrm{AIC}$ from the top model) affecting the occurrence of $O$. eremita in BCWT. The data were obtained during 2015 in the two macroareas PA and FC (PA= Parco Nazionale d'Abruzzo Lazio e Molise; FC = Parco Nazionale delle Foreste Casentinesi).

\begin{tabular}{ccccc}
\hline Model & $\boldsymbol{K}$ & $\mathbf{- 2 \operatorname { L o g } ( L )}$ & $\boldsymbol{\Delta A I C}$ & $\boldsymbol{w}$ \\
\hline$\left.\psi\left({ }_{\mathrm{HN}}\right), p()_{t}\right)$ & 18 & 492.66 & 0.00 & 0.50 \\
$\left.\psi\left(\mathrm{HN}+\mathrm{MA}_{\mathrm{MA}}\right), p_{t}\right)$ & 19 & 492.29 & 1.63 & 0.22 \\
\hline
\end{tabular}

*Occupancy $(\psi)$ and detection $(p)$ probabilities are considered. $\mathrm{HN}=$ holes number; $\mathrm{MA}=$ microhabitats amount. $K$ represents the number of parameters in the model, $w$ the Akiake weight and $-2 \log (L)$ is twice the negative log-likelihood value. Akaike Information Criteria $(\triangle \mathrm{AIC})$ were calculated for each model (Burnham and Anderson 2002).

Table 9. Dataset of mark-recapture during 2016. Summary of mark-recapture data obtained during the study of O. eremita in Italy with different capture methods during 2016 in the two macroareas, PA and FC $(\mathrm{BCWT}=$ Black Cross Windows Traps; PT = Pitfall Traps; PA= Parco Nazionale d'Abruzzo Lazio e Molise; FC = Parco Nazionale delle Foreste Casentinesi; DP = Difesa di Pescasseroli; FL = Foresta della Lama).

\begin{tabular}{|c|c|c|c|c|}
\hline \multirow[b]{2}{*}{ Site } & \multicolumn{2}{|c|}{ BCWT } & \multicolumn{2}{|c|}{ PT } \\
\hline & $\begin{array}{c}\text { Marked beetles } \\
\left(/{ }^{\wedge}\right)\end{array}$ & $\begin{array}{c}\text { Recapture events } \\
((\& / \overbrace{}^{\lambda})\end{array}$ & $\begin{array}{c}\text { Marked beetles } \\
\left(\left(/ / \delta^{\lambda}\right)\right.\end{array}$ & $\begin{array}{c}\text { Recapture events } \\
((/ \curvearrowright)\end{array}$ \\
\hline DP & $22 / 9$ & $1 / 0$ & $0 / 0$ & $0 / 0$ \\
\hline FL & $5 / 5$ & $1 / 0$ & $0 / 0$ & $0 / 0$ \\
\hline
\end{tabular}

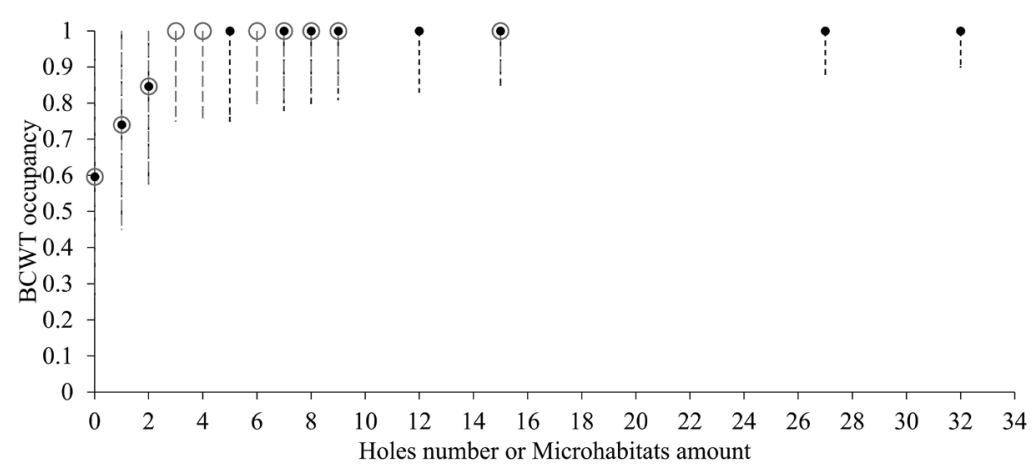

Figure 9. BCWT occupancy data. BCWT occupancy of $O$. eremita during 2015 in relation to the number of holes (grey empty circles) and microhabitat amount (black dots). Vertical bars indicate the standard error. 


\section{Discussion}

\section{The standard method for the monitoring of O. eremita}

Comparison of the results obtained from all methods allowed the best standard method for the monitoring of $O$. eremita to be selected. The analysis of the total number of hermit beetles captured by the two trap types during the sampling of 2015 and 2016 in the two macroareas (FC and PA) showed that only BCWT captured the beetles. The use of PT provided zero captures in this research, notwithstanding this method was successfully used in different environmental contexts, such as in Sweden and France (Ranius 2000, 2001, 2007, Vignon 2015) until the identification of the sex pheromone of $O$. eremita and its now consolidated use as bait for BCWT (Larsson et al. 2003, Larsson and Svensson 2009, 2011). In the past years, many researchers chose to use a combination of BCWT and PT, as the first method is able to capture a higher number of individuals (with a high prevalence of females), while the second is able to capture a high number of males (Ranius 2001, Ranius and Hedin 2001, Svensson et al. 2011, Chiari et al. 2013a). Previous research in central Italy (Chiari et al. 2013a) reported that PT can be considered a good and cheap method, but it required much field effort and time in terms of setting and checking traps. In fact, PT was successful to a limited extent in Italy when a very high number of traps was used, as reported in Chiari et al. (2013a), 116 PT being used and checked every second day from the middle of June to the first week of August 2009, obtaining only 19 individuals. This low number of individuals, despite the high field effort and the 0 value obtained by the MIPP sampling (present paper) is probably due to the low density of Italian populations in the southern part of the hermit beetle geographic range and the reduced volume of tree hollows (associated with the young age of trees). In Sweden, where the habitat conditions are more favourable for the species (older trees and larger hollows with plenty of wood mould), the number of hermit beetles collected by PT is usually higher (Ranius et al. 2005).

These results suggested that, to carry out monitoring of a southern population of the hermit beetle (at least for the Apennine range), a number of $30 \mathrm{BCWT}$ checked every second day for eight weeks (from early July to the end of August) is the most efficient method; traps can also be placed on trees without hollows due to the high attraction of the pheromone on the species. The activity period can vary according to altitude and latitude, other than seasonal weather conditions and then the sampling period for monitoring could be shorter where there is a greater knowledge of the life cycle of the species at local level (e.g. Figure 8). If no direct information is available on the activity period at local level, a preliminary study should be conducted in the previous year to obtain information. The BCWT showed differences in capture of the sexes, with a significant bias towards females (Tables 2, 5 and 9). Such strong attraction on females may produce a disturbing effect on breeding activity and behaviour, with the risk of reducing the birth rate of the local population. For this reason, precautionary measures should be taken even if the cause and effect relationships between distur- 
bance by pheromone and population density of hermit beetles are not fully established scientifically. The authors' advice is to conduct BCWT monitoring every three years (one year of sampling separated by two years without sampling).

A high number of PT (at least 150) placed in the same number of tree cavities (preferably one trap per tree) may be used as an alternative method. In fact, this method is cheaper and less invasive (due to the breeding activities by pheromones not being disturbed), but may be used only in areas where: 1) tree hollows are abundant, large enough and with sufficient amounts of wood mould to set pitfall traps and 2) the team is composed of several people in order to ensure the checking of so many traps every two days.

According to N. Jansson (pers. com.), the bottom of the traps (both BCWT and PT) should be lined with wet moss, in order to reduce temperature, drought, stress and energy consumption of the beetles captured.

\section{Protocol, materials and equipment}

The first step in carrying out the monitoring plan is to choose a suitable area inhabited by $O$. eremita. Ideally, an area should be investigated in detail, in order to map the hollow tree by GPS, to take photographs and to record the characteristics of the trees (e.g. species, size, DBH, height, number of hollows etc.). This information, gathered in the field, will be useful for setting the traps. Afterwards, the BCWT would be built during the spring, before starting the monitoring. (For details and materials about the BCW'T, see Methods and supplementary file 1.) The traps are set in the field at least a week before starting the sampling, without both pheromone and plastic collecting jars. The BCWT could be positioned randomly in a woodland or along a transect (e.g. along tree-lined streets, rows of pollarded trees bordering rivers and channels etc.) or in a grid (e.g. 5 rows with 6 traps in each one; the size of the grid is about $500 \mathrm{~m}$ long and $600 \mathrm{~m}$ wide), setting the traps at least $100 \mathrm{~m}$ from each other. Every trap should be mapped by GPS and marked by a label with its number.

The monitoring can be carried out by two operators checking the traps every two days for 8 weeks, from July to September. The surveys can be conducted in two different ways:

Three times a week (Monday, Wednesday and Friday), the traps can be activated the day before starting the check (Sunday) and deactivated after the third weekly check, on Friday. The BCWT is activated when the caps of the plastic collection jar are removed and the eppendorf vial with pheromone is baited; in the opposite case, deactivation means that the collection jar is closed and the eppendorf vial has been removed. The activation and deactivation of the traps is crucial to avoid the death of individuals.

Every two days without any breaks, continuously; the traps can be activated the day before to start the check and never deactivated until the end of sampling.

The plastic eppendorf vials (capacity of $1.5 \mathrm{ml}$ ) loaded with $1200 \mu \mathrm{l}$ of the racemic mixture of $\gamma$-decalactone can be prepared before starting the sampling and preserved in a freezer. It is suggested that the pheromone vials be changed once a week. 
The protocol requires the presence of two operators who should fill the field sheet of each survey with the date, the weather conditions (rain and cloud) and the starting time (see supplementary file 2). After that, the operators check the traps and, once an adult is found, it is temporarily placed into the plastic jar with the cap to prevent escape. Once the check of BCWT has been completed, the number of individuals collected is counted, specifying the number of males and females for each trap in the field sheet (see supplementary file 2). Afterwards, the beetles were released in the same hollow tree from where they were captured. At the end of each survey, the operators recorded the weather conditions (rain and cloud) and the finishing time (see supplementary file 2).

The equipment required is: GPS, clipbord, field sheet, pencil, clock, plastic eppendorf vial with pheromone, cotton dental rolls, tweezers and camera.

\section{Constraints, spatial validity and possible interferences}

O. eremita is a species with a low dispersal rate. In fact, the majority of the individuals can move only a few hundred metres (from $100 \mathrm{~m}$ to $250 \mathrm{~m}$ ), while some have a dispersal rate exceeding $2000 \mathrm{~m}$, as reported in several studies summarised by Chiari et al. 2013b. The dispersal rate seems to vary with latitude from southern to northern Europe, in relation to the mean temperatures and to the characteristics of the habitat (Larsson and Svensson 2009, 2011, Ranius et al. 2011, Chiari et al. 2013b). This means that the spatial validity of the method must be evaluated in relation to the local dispersal rate for different populations.

The major risk associated with the use of the BCWT is related to adverse weather conditions; in fact, in case of heavy rains, the plastic collection bottle, despite the presence of drainage holes, may be filled by water, resulting in an obvious danger to the specimens trapped inside. In case of heavy rainfall, it is recommended to increase the rate of checks, verifying daily if there are specimens inside the traps and emptying water from the collection chambers and from any material that can clog the holes (e.g. leaves).

Finally, O. eremita is a rare and elusive species, very sought after by collectors and the specimens trapped inside BCWT may represent easy prey for them. Thus, to avoid risks related to unauthorised collections, it is recommended to set the traps on higher branches with the help of an extension, so that the traps are not easily accessible.

\section{Counting, quantification and data sharing}

In order to identify the population trend for $O$. eremita at local level during the years, a reference value can be calculated as follows:

1. For each survey, sum the total number of individuals (males + females) captured by all 30 BCWT.

2. Calculate the mean value of the number of individuals from all surveys, excluding the survey with the lowest number. Removing the lowest number, 
as proposed for other insect species (FLA 2014, Hardersen and Toni 2015), allows the elimination of eventual outlier values due to adverse climatic conditions (e.g. low temperature and/or rainfall) or other factors, that may affect the activity of the individuals and increase data heterogeneity.

Table 10 reports an example of calculation of the mean value obtained for identifying a population trend. This value allows the comparison of long-term data from the same location and to identify a population trend.

Table 10. Example of calculation of mean value of captured beetles. Subset of traps and surveys used for calculation of the reference value of the monitoring trend of O. eremita population in one site (BCWT: Black Cross Window Trap).

\begin{tabular}{ccccccccc}
\hline Survey & BCWT 1 & BCWT 2 & BCWT 3 & BCWT 4 & BCWT 5 & BCWT 6 & BCWT 7 & Total \\
\hline 1 & 1 & 2 & 4 & 3 & 2 & 3 & 1 & 16 \\
2 & 3 & 6 & 5 & 5 & 6 & 3 & 3 & 31 \\
3 & 3 & 5 & 7 & 7 & 7 & 4 & 5 & 38 \\
4 & 2 & 4 & 3 & 2 & 2 & 0 & 0 & 13 \\
5 & 4 & 7 & 8 & 5 & 3 & 5 & 4 & 36 \\
\hline \multicolumn{7}{l}{ Average value for the four counts with the highest average total }
\end{tabular}

\section{Acknowledgements}

The present work was developed within the EU project LIFE11 NAT/IT/000252, with the contribution of the LIFE financial instrument of the European Union. We are grateful to all the staff of the National Forestry service, local biodiversity office of Castel di Sangro, in particular to Tiziana Altea, Mario Romano, Lucia Eusepi, Federica Desprini, Ilaria Filippone; to all the staff of the National Forestry service, local biodiversity office of Pratovecchio, in particular to Giovanni Quilghini, Antonio Zoccola, Barbara Rossi, Sandro Marsella, Silvia Bertinelli, Valerio Mazzoli and Angelo Lamberti; to all the staff of Parco Nazionale d'Abruzzo, Lazio e Molise, in particular to Dario Febbo, Cinzia Sulli and Paola Tollis and all the park rangers; to the staff of the Foreste Casentinesi, Monte Falterona e Campigna National Park and Cooperativa "In Quiete" and their volunteers. We would like to thank our colleagues and field assistants who helped during the surveys: Emiliano Mancini, Lara Redolfi De Zan, Ilaria Toni, Alessandro Cini, Sonke Hardersen, Sarah Rossi De Gasparis, Giulio Nigro, Marco Molfini, Francesca Bernardini, Emma Pellegrini, Randi Rollins, Sara Amendolia, Giulia Albani Rocchetti, Fabio Garzuglia, Rosaria Santoro, Sara Benelli, Valentina Stagno, Marco Boscaro, Silvia De Michelis, Cristina Mantoni, Nino Loreto, Davide Caprioli, Alessandro Cortini, Matteo De Santis, Daniele Di Giacomo, Giulia Caruso, Eleonora Cammarano, Ilaria Zappitelli, Kevin Mancini, Flavio Cennamo, Giacomo Grosso, Gioia Burini, Silvio Kroha, Federico Grant, Luca Gallitelli, Livia Benedini, Emilia Capogna, Elisa Tamilia, Laura Petruccelli, Michela Perrone, Adriano Sanno, Gabriele Miserendino, Alessandro Morelli, Luca Bisegna, Cristiana Baldi, Luciano Caporale and Emanuela Rosi. We would like to thank everyone for allowing us to use their 
photos (Alberto Ballerio, Benjamin Calmont, Sonia Dourlot, Federico Romiti, Marco Uliana, Francesca Bernardini, Emilia Capogna, Stefano Chiari).We thank Meike Liu (Sapienza - Università di Roma, Dipartimento "Charles Darwin", Italia and Northwest A\&F University of Yangling, China) for preparing the new version of the European distribution map of the genus Osmoderma.

A special permit was obtained from the Italian Ministry of Environment for handling and capturing individuals of the target species (collection permit: Ministero dell'Ambiente e della Tutela del Territorio e del Mare - DG Protezione della Natura e del Mare, U. prot PNM 2012-0010890 del 28/05/2012).
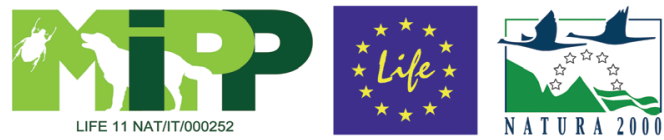

With the contribution of the LIFE financial instrument of the European Union.

\section{References}

Ahrens D (2006) The phylogeny of Sericini and their position within the Scarabaeidae based on morphological characters (Coleoptera: Scarabaeidae). Systematic Entomology 31: 113144. https://doi.org/10.1111/j.1365-3113.2005.00307.x

Ahrens D, Schwarzer J, Vogler AP (2014) The evolution of scarab beetles tracks the sequential rise of angiosperms and mammals. Proceedings of the Royal Society B 281: 1470. https:// doi.org/10.1098/rspb.2014.1470

Alexander K, Buche B, Dodelin B, Schlaghamersky J (2010) Osmoderma barnabita. The IUCN Red List of Threatened Species 2010: e.T157901A5169119.

Audisio P, Ballerio A, Carpaneto GM, Antonini G, Mancini E, Coletti G, Piattella E, De Biase A (2003) Osmoderma eremita s.l. in Europa meridionale: stato delle conoscenze e problemi di conservazione (Coleoptera, Cetoniidae). In: Mason F, Nardi G, Tisato M (Eds) Atti del Simposio Internazionale Legno morto: una chiave per la biodiversità / Proceedings of the International Symposium Dead wood: a key to biodiversity (Mantova, 29-31 May 2003). Sherwood 95, 57-60.

Audisio P, Brustel H, Carpaneto GM, Coletti G, Mancini E, Piattella E, Trizzino M, Dutto M, Antonini G, De Biase A (2007) Updating the taxonomy and distribution of the European Osmoderma, and strategies for their conservation (Coleoptera, Scarabaeidae, Cetoniinae). Fragmenta Entomologica 39: 273-290. https://doi.org/10.4081/fe.2007.124

Audisio P, Brustel H, Carpaneto GM, Coletti G, Mancini E, Trizzino M, Antonini G, De Biase A (2009) Data on molecular taxonomy and genetic diversification of the European Hermit beetles, a species-complex of endangered insects (Coleoptera: Scarabaeidae, Cetoniinae, Osmoderma). Journal of Zoological Systematics and Evolutionary Research 47: 88-95. https://doi.org/10.1111/j.1439-0469.2008.00475.x

Audisio P, Baviera C, Carpaneto GM, Biscaccianti AB, Battistoni A, Teofili C, Rondinini C (2014) Lista Rossa IUCN dei Coleotteri saproxilici Italiani. Comitato Italiano IUCN e 
Ministero dell'Ambiente e della Tutela del Territorio e del Mare, Roma, 132 pp. http:// www.iucn.it/classe-insecta.php.

Ballerio A, Rey A, Uliana M, Rastelli M, Rastelli S, Romano M, Colacurcio L (2010) Coleotteri Scarabeoidei d'Italia. Marco Serra Tarantola Editore, Rodegno Saiano.

Balthasar V (1963) Monographie der Scarabaeidae und Aphodiidae der Paläarktischen und Orientalischen Region (Coleoptera: Lamellicornia). Band 1. Tschechoslowak Akademie der Wissenschaften, Praha, 287 pp.

Baratelli D (2004) Note sulla presenza di Osmoderma eremita Scopoli, 1763, in un biotopo umido prealpino, e interventi gestionali mirati alla conservazione della specie. Bollettino della Società Ticinese di Scienze Naturali 92: 83-90.

Baraud J (1977) Coléoptères Scarabaeoidea. Faune de l'Europe occidentale: Belgique, France, Grande-Bretagne, Italie, Péninsule ibérique. Supplément à la Nouvelle Revue d'Entomologie 7: 1-352.

Baraud J (1992) Coléoptères Scarabaeoidea d'Europe. Fédération française des Sociétés de Sciences naturelles, Paris, \& Société linnéenne de Lyon, 873 pp.

Bărbuceanu D, Niculescu M, Boruz V, Niculescu L, Stoleriu C, Ursu A (2015) Protected saproxylic Coleoptera in "the Forests in the southern part of the Cândeşti Piedmont", a Romanian Natura 2000 Protected Area.

Barclay MVL (2007) Comment on the proposed conservation of the generic names Gnorimus Le Peletier de Saint-Fargeau \& Serville, 1828 and Osmoderma Le Peletier de Saint-Fargeau \& Serville, 1828 (Insecta, Coleoptera) (Case 3349; BZN 63: 177-183). Bulletin of Zoological Nomenclature 64: 122.

Bezborodov VG (2016) The Genus Osmoderma (Coleoptera, Scarabaeidae, Trichiinae) in Siberia and the Russian Far East. Entomological Review 95: 1088-1098. https://doi. org/10.1134/S0013873815080151

Bologna MA, Rovelli V, Zapparoli M (2016) Osmoderma eremita (Scopoli, 1763) (Scarabeo eremita), O. italicum Sparacio, 2000, O. cristinae Sparacio, 1994. In: Stoch F, Genovesi $\mathrm{P}$ (Ed.) Manuali per il monitoraggio di specie e habitat di interesse comunitario (Direttiva 92/43/CEE) in Italia: specie animali. ISPRA, Serie Manuali e linee guida, 141/2016, 64-65.

Bouchard P, Bousquet Y, Davies AE, Alonso-Zarazaga MA, Lawrence JF, Lyal CHC, Newton AF, Reid CAM, Schmitt M, Slipinski SA, Smith ABT (2011) Family-group names in Coleoptera (Insecta). ZooKeys 88: 1-972. https://doi.org/10.3897/zookeys.88.807

Boving AG, Craighead FC (1931) An illustrated synopsis of the principal larval forms of the Order Coleoptera. Brooklyn Entomological Society, New York, 351 pp.

Brandmayr P, Casale A, Puzzo F, Scalercio S (2005) Analisi cronogeonemica: alcuni esempi con riferimento alle specie della fauna italiana incluse nella Direttiva Habitat. In: Ruffo S, Stoch F (Eds) Checklist e distribuzione della fauna italiana. Memorie del Museo Civico di Storia Naturale di Verona (2 serie), Sezione Scienza della Vita 16: 41-45.

Britton EB (1956) Coleoptera Scarabaeoidea. Handbooks for the Identification of British Insects 5: 1-29.

Browne DJ, Scholtz CH (1995) Phylogeny of the families of Scarabaeoidea (Coleoptera) based on characters of the hindwing articulation, hindwing base and wing venation. Systematic Entomology 20: 145-173. https://doi.org/10.1111/j.1365-3113.1995.tb00089.x 
Browne DJ, Scholtz CH (1998) Evolution of the scarab hindwing articulation and wing base: a contribution toward the phylogeny of the Scarabaeidae (Scarabaeoidea: Coleoptera). Systematic Entomology 23: 307-326. https://doi.org/10.1046/j.1365-3113.1998.00059.x

Browne DJ, Scholtz CH (1999) A phylogeny of the families of Scarabaeoidea (Coleoptera). Systematic Entomology 24: 51-84. https://doi.org/10.1046/j.1365-3113.1999.00067.x

Burnham KP, Anderson DR (2002) Model selection and multimodel inference: a practical information-theoretic approach. Springer, Berlin, 488 pp. https://doi.org/10.1007/b97636

Bußler H, Müller J (2009) Vacuum cleaning for conservationists: a new method for inventory of Osmoderma eremita (Scop., 1763)(Coleoptera: Scarabaeidae) and other inhabitants of hollow trees in Natura 2000 areas. Journal of Insect Conservation 13: 355-359. https:// doi.org/10.1007/s10841-008-9171-4

Byk A, Borowski J, Mazur S, Mokrzycki T, Rutkiewicz A (2013) Waloryzacja lasów Leśnego Kompleksu Promocyjnego" Lasy Spalsko-Rogowskie" na podstawie struktury zgrupowań chrzązczy saproksylicznych. Studia i Materiały Centrum Edukacji Przyrodniczo-Leśnej 15: 35.

Campanaro A, Bardiani M, Spada L, Carnevali L, Montalto F, Antonini G, Mason F, Audisio P (2011) Linee guida per il monitoraggio e la conservazione dell'entomofauna saproxilica. Quaderni Conservazione Habitat 6, Cierre Grafica (Verona, 1-8. [CD-ROM]

Carlsson S, Bergman K-O, Jansson N, Ranius T, Milberg P (2016) Boxing for biodiversity: evaluation of an artificially created decaying wood habitat. Biodiversity and Conservation 25: 393-405. https://doi.org/10.1007/s10531-016-1057-2

Carpaneto GM, Piattella E, Valerio L (2005) Insecta Coleoptera Scarabaeoidea. In: Ruffo S, Stoch F (Eds) Checklist e distribuzione della fauna italiana. Memorie del Museo Civico di Storia Naturale di Verona (2 serie), Sezione Scienza della Vita 16, 193-197.

Carpaneto GM, Mazziotta A, Coletti G, Luiselli L, Audisio P (2010) Conflict between insect conservation and public safety: the case study of a saproxylic beetle (Osmoderma eremita) in urban parks. Journal of Insect Conservation 14: 555-565. https://doi.org/10.1007/ s10841-010-9283-5

Carpaneto GM, Baviera C, Biscaccianti AB, Brandmayr P, Mazzei A, Mason F, Battistoni A, Teofili C, Rondinini C, Fattorini S, Audisio P (2015) A Red List of Italian Saproxylic Beetles: taxonomic overview, ecological features and conservation issues (Coleoptera). Fragmenta entomologica 47: 53-126.

Carpaneto GM, Campanaro A, Hardersen S, Audisio P, Bologna MA, Roversi PF, Sabbatini Peverieri G, Mason F (2017) The LIFE Project "Monitoring of insects with public participation” (MIPP): aims, methods and conclusions. In: Carpaneto GM, Audisio P, Bologna MA, Roversi PF, Mason F (Eds) Guidelines for the Monitoring of the Saproxylic Beetles protected in Europe. Nature Conservation 20: 1-35. https://doi.org/10.3897/natureconservation.35.12761

Cerretti P (2008) Osmoderma eremita. In: Manuale di indirizzo per la gestione delle aree tutelate del Friuli Venezia Giulia, Progetto "SARA Sistema Aree Regionali Ambientali - Costituzione del Sistema regionale delle aree naturali”. Allegato B. http://www.regione.fvg.it/rafvg/cms/RAFVG/

Chiari S, Carpaneto GM, Zauli A, Marini L, Audisio P, Ranius T (2012) Habitat of an endangered saproxylic beetle, Osmoderma eremita, in Mediterranean woodlands. Ecoscience 19: 299-307. https://doi.org/10.2980/19-4-3505 
Chiari S, Zauli A, Mazziotta A, Luiselli L, Audisio P, Carpaneto GM (2013a) Surveying an endangered saproxylic beetle, Osmoderma eremita, in Mediterranean woodlands: a comparison between different capture methods. Journal of Insect Conservation 17: 171-181. https://doi.org/10.1007/s10841-012-9495-y

Chiari S, Carpaneto GM, Zauli A, Zirpoli GM, Audisio P, Ranius T (2013b) Dispersal patterns of an endangered saproxylic beetle, Osmoderma eremita, in Mediterranean woodlands. Insect Conservation and Diversity 6: 309-318. https://doi.org/10.1111/j.17524598.2012.00215.x

Chiari S, Zauli A, Audisio PA, Carpaneto GM (2014) Interactions between larvae of the threatened saproxylic beetle Osmoderma eremita and other flower chafers in Mediterranean woodlands: Implications for conservation. Insect Conservation and Diversity 7(5): 462-469. https://doi.org/10.1111/icad.12069

Dubois G (2009) Écologie des coléoptères saproxyliques: Biologie des populations et conservation d'Osmoderma eremita (Coleoptera: Cetoniidae). Thèse $\mathrm{PhD}$, Université de Rennes 1, École doctorale Vie-Agro-Santé, Paimpont, 262 pp.

Dubois G, Vignon V (2008) First results of radio tracking of Osmoderma eremita (Coleoptera: Cetoniidae) in French chestnut orchards. In: Vignon V, Asmodé J-F (Eds) Proceedings of the $4^{\text {th }}$ Symposium and workshop on the conservation of Saproxylic Beetles (Vivoin, France, $2^{\text {th }}-29^{\text {th }}$ June, 2006). Revue d'Écologie (Terre et Vie) 63: 123-130.

Dubois GF, Vignon V, Delettre YR, Rantier Y, Vernon P, Burel F (2009) Factors affecting the occurrence of the endangered saproxylic beetle Osmoderma eremita (Scopoli, 1763) (Coleoptera: Cetoniidae) in an agricultural landscape. Landscape and urban Planning 91: 152-159. https://doi.org/10.1016/j.landurbplan.2008.12.009

Dubois G, Le Gouar P, Delettre Y, Brustel H, Vernon P (2010) Sex-biased and body condition dependent dispersal capacity in the endangered saproxylic beetle Osmoderma eremita (Coleoptera: Cetoniidae). Journal of Insect Conservation 14: 679-687. https://doi. org/10.1007/s10841-010-9296-0

Dutto M (2005) Osservazioni biologiche su Osmoderma eremita (Scopoli, 1753) ed altri Scarabaeoidea Pleurosticta in vecchi pioppi del Cuneese (Coleoptera Scarabaeoidea). Naturalista siciliano 29: 89-91.

Freude H, Harde KW, Lohse GA (1969) Kafer Mitteleuropas. Band 8. Teredilia (Lyctidae - Ptinidae), Heteromera (Oedemeridae - Boridae), Lamellicornia (Scarabaeidae, Lucanidae). Spektrum Akademischer Verlag, Berlin, 388 pp.

Giangregorio P, Audisio P, Carpaneto GM, Marcantonio G, Maurizi E, Mosconi F, Campanaro A (2015) Updated distribution of Osmoderma eremita in Abruzzo (Italy) and agro-pastoral practices affecting its conservation (Coleoptera: Scarabaeidae). Fragmenta Entomologica 47: 139-146. https://doi.org/10.4081/fe.2015.142

Gusakov AA (2002) Scarabaeid beetles of the subfamily Trichiinae (Coleoptera, Scarabaeidae) in the Fauna of Russia - Species of the genus Gymnodus Kirby, 1827. Eidos, Kaluga, 1-55. [In Russian]

Hedin J, Ranius T (2002) Using radio telemetry to study dispersal of the beetle Osmoderma eremita, an inhabitant of tree hollows. Computers and Electronics in Agriculture 35: 171180. https://doi.org/10.1016/S0168-1699(02)00017-0 
Hedin J, Ranius T, Nilsson SG, Smith HG (2008) Restricted dispersal in a flying beetle assessed by telemetry. Biodiversity and Conservation 17: 675-684. https://doi.org/10.1007/ s10531-007-9299-7

Hilszczański J, Jaworski T, Plewa R, Jansson N(2014) Surrogate tree cavities: boxes with artificial substrate can serve as temporary habitat for Osmoderma barnabita (Motsch.) (Coleoptera, Cetoniinae). Journal of Insect Conservation 18: 855-861. https://doi.org/10.1007/ s10841-014-9692-y

Hines JE, MacKenzie DI (2004) PRESENCE, vers. 4.0. http://www.mbrpwrc.usgs.gov/software.html

Howden HF (1968) A review of the Trichiinae of North and Central America (Coleoptera: Scarabaeidae). Memoirs of the Entomological Society of Canada 54: 1-77. https://doi. org/10.4039/entm $10054 \mathrm{fv}$

ICZN (2007) Opinion 2186 (Case 3349). Gnorimus Le Peletier de Saint-Fargeau \& Serville, 1828, and Osmoderma Le Peletier de Saint-Fargeau \& Serville, 1828 (Insecta, Coleoptera, Scarabaeidae): conserved. Bulletin of Zoological Nomenclature 64: 265-266.

Iorgu IS, Surugiu V, Gheoca V, Popa OP (2015) Ghid Sintetic pentru Monitorizarea Speciilor de Nevertebrate de Interes Comunitar din România. București, 159 pp.

Joy NH (1932) A practical Handbook of British Beetles. Witherby, London, 194 pp.

Jansson N, Ranius T, Larsson A, Milberg P (2009). Boxes mimicking tree hollows can help conservation of saproxylic beetles. Biodiversity and Conservation 18: 3891-3908. https:// doi.org/10.1007/s10531-009-9687-2

Jönsson N, Méndez M, Ranius T (2004) Nutrient richness of wood mould in tree hollows with the Scarabaeid beetle Osmoderma eremita. Animal Biodiversity and Conservation 27: 79-82.

Juillerat L, Vögeli M (2004) Gestion des vieux arbres et maintien des Coléoptères saproxyliques en zone urbaine et periurbaine. Centre Suisse de Cartographie de la Faune, Neuchatel, 20 pp.

Jurc M, Ogris N, Pavlin R, Borkovic D (2008) Forest as a habitat of saproxylic beetles on Natura 2000 sites in Slovenia. Revue d'Écologie (Terre et Vie) 63: 53-66.

Kalas JA, Viken Å, Bakken T (2006) Norwegian Red List: 416. Norwegian Biodiversity Information Centre, Trondheim. [in Norwegian and English]

Klausnitzer BD, Krell FT (1997) Uberfamilie: Scarabaeoidea. In: Klausnitzer BD (Ed.) Die Larven der Kafer Mitteleuropas. Band 3, Polyphaga, Teil 2. Gustav Fischer Verlag, Jena, 11-89.

Kraus D, Bütler R, Krumm F, Lachat T, Larrieu L, Mergner U, Paillet Y, Rydkvist T, Schuck A, Winter S (2016) Catalogue of tree microhabitats - Reference field list. European Forest Institute, 16 pp. Krell FT (1997) Zu Taxonomie, Chorologie und Eidonomie einiger westpalaearktischer Lamellicornia (Coleoptera). Entomologische Nachrichten und Berichte 40: 217-229.

Krell FT, Ballerio A, Smith ABT, Audisio P (2006) Case 3349. Gnorimus Le Peletier de Saint-Fargeau \& Serville, 1828, and Osmoderma Le Peletier de Saint-Fargeau \& Serville, 1828 (Insecta, Coleoptera): proposed conservation of the generic names. Bulletin of the Zoological Nomenclature 63(3): 177-183.

Krikken J (1984) A new key to the suprageneric taxa in the beetle family Cetonidae, with annotated lists of the known genera. Zoologische Verhandelingen 210: 1-75.

Landvik M, Wahlberg N, Roslin T (2013) The identity of the Finnish Osmoderma (Coleoptera: Scarabaeidae, Cetoniinae) population established by COI sequencing. Entomolia Fennica 24: 147-155. 
Landvik M, Niemelä P, Roslin T (2016) Opportunistic habitat use by Osmoderma barnabita (Coleoptera: Scarabaeidae), a saproxylic beetle dependent on tree cavities. Insect Conservation and Diversity 9: 38-48. https://doi.org/10.1111/icad.12141

Larsson MC, Hedin J, Svensson GP, Tolasch T, Francke W (2003) Characteristic odor of Osmoderma eremita identified as a male-released pheromone. Journal of Chemical Ecology 29: 575-587. https://doi.org/10.1023/A:1022850704500

Larsson MC, Svensson GP (2009) Pheromone monitoring of rare and threatened insects: exploiting a pheromone-kairomone system to estimate prey and predator abundance. Conservation Biology 23:1516-1525. https://doi.org/10.1111/j.1523-1739.2009.01263.x

Larsson MC, Svensson GP (2011) Monitoring spatiotemporal variation in abundance and dispersal by a pheromone-kairomone system in the threatened saproxylic beetles Osmoderma eremita and Elater ferrugineus. Journal of Insect Conservation 15: 891-902. https://doi. org/10.1007/s10841-011-9388-5

Latreille PA, Lepeletier de Saint-Fargeau A, Guérin-Méneville FE (1825) Entomologie, ou Histoire Naturelle de Crustacées, des Arachnides et des Insectes ( $10^{\text {th }}$ edn). Agasse, Paris, 833 pp.

Lawrence JF, Newton AF (1995) Families and subfamilies of Coleoptera (with selected genera, notes, references and data on family-group names). In: Pakaluk J, Slipínski SA (Eds), Biology, Phylogeny, and Classification of Coleoptera. Papers Celebrating the 80th Birthday of R. A. Crowson. Muzeum i Instytut Zoologii PAN, Warszawa, 779-1006.

Le Gouar PJ, Dubois GF, Vignon V, Brustel H, Vernon P (2015) Demographic parameters of sexes in an elusive insect: implications for monitoring methods. Population Ecology 57: 227-236. https://doi.org/10.1007/s10144-014-0453-2

Lepeletier de Saint-Fargeau A, Audinet-Serville JG (1828) Scarabé. In Latreille PA, Entomologie, ou Histoire naturelle des Crustacées, des Arachnides et des Insectes. Encyclopedie methodique 10, Paris, 346-382.

Luce J-M (1995) Écologie des cétoines (Insecta: Coleoptera) microcavernicoles de la forêt de Fontainbleau: niches écologiques, relations interspécifiques et conditions de conservation des populations. Thèse de doctorat en Ecologie générale. École doctorale Sciences de la nature et de l'Homme, Muséum National d'Histoire Naturelle, Paris, 1-166.

Luce J-M (1996) Osmoderma eremita (Scopoli, 1763). In: van Helsdingen PJ, Willemse L, Speight MCD (Eds) Background information on invertebrates of the Habitats Directive and the Bern Convention. Part I: Crustacea, Coleoptera and Lepidoptera. Council of Europe, Strasbourg, 64-69.

Luce J-M (2001) La Cétoine protégée Osmoderma eremita (Scopoli, 1763) peut elle être un outil de gestion de la biodiversité? In: Robert J-C, Guilbot R, Dommanget J-L, Maurin $\mathrm{H}$ (Eds) Inventaire et Cartographie des invertebrés comme contribution à la gestion des milieu naturels français. Actes du séminaire tenu à Besançon les 8, 9 et 10 Juillet 1999, Patrimoines naturels, Muséum National d'Histoire Naturelle, Besançon, 243-263.

Lüchte W, Klausnitzer B (1998) Die Käfer Mitteleuropas. 4 Supplementband. Goecke \& Evers, Krefeld -Im Gustave Fischer Verlag, Jena, Stuttgart, Lübeck, Ulm, 398 pp.

MacKenzie DI, Royle JA (2005) Designing occupancy studies: general advice and allocating survey effort. Journal of Applied Ecology 42:1105-1114. https://doi.org/10.1111/j.13652664.2005.01098.x 
MacKenzie DI, Nichols JD, Royle JA, Pollock KH, Bailey LL, Hines JE (2006) Occupancy Estimation and Modeling: Inferring Patterns and Dynamics of Species Occurrence. Academic Press, New York

Martin-Piera F, López-Colón JI (2000) Fauna Iberica, Vol. 14. Coleoptera Scarabaeoidea I. Museo Nacional de Ciencias Naturales, Consejo Superior de Investigaciones Científicas, Madrid.

Mason F, Roversi PF, Audisio P, Bologna MA, Carpaneto GM, Antonini G, Mancini E, Sabbatini Peverieri G, Mosconi F, Solano E, Maurizi E, Maura M, Chiari S, Sabatelli S, Bardiani M, Toni I, Redolfi De Zan L, Rossi de Gasperis S, Tini M, Cini A, Zauli A, Nigro G, Bottacci A, Hardersen S, Campanaro A (2015) Monitoring of insects with public participation (MIPP; EU LIFE project 11 NAT/IT/000252): overview on a citizen science initiative and a monitoring programme (Insecta: Coleoptera; Lepidoptera; Orthoptera). Fragmenta entomologica 47: 51-52. https://doi.org/10.4081/fe.2015.134

Massa B (1995) Osmoderma heremitum meridionale Tauzin 1994, sinonimo di Osmoderma cristinae Sparacio 1994. Naturalista siciliano 19: 307-308.

McKenna DD, Farrell BD, Caterino MS, Farnum CW, Hawks DC, Maddison DR, Seago AE, Short AEZ, Newton AF, Thayer MK (2015) Phylogeny and evolution of Staphyliniformia and Scarabaeiformia: forest litter as a stepping stone for diversification of nonphytophagous beetles. Systematic Entomology 40: 35-60. https://doi.org/10.1111/syen.12093

Medvedev SI (1953) A new species of Osmoderma Serville (Coleoptera, Scarabaeidae) from Georgia. Entomologicheskoe Obozrenie 32: 297-299.

Micó E, Galante E (2003a) Larval morphology and biology of four Netocia and Potosia species (Coleoptera: Scarabaeoidea: Cetoniidae: Cetoniinae). European Journal of Entomology 100: 131-142. https://doi.org/10.14411/eje.2003.023

Micó E, Galante E (2003b) Biology and new larval descriptions for three cetoniine beetles (Coleoptera: Scarabaeidae: Cetoniinae: Cetoniini: Cetoniina, Leucocelina). Annals of the Entomological Society of America 96(2): 95-106. https://doi.org/10.1603/00138746(2003)096[0095:BANLDF]2.0.CO;2

Mosconi F, Campanaro A, Carpaneto GM, Chiari S, Hardersen S, Mancini E, Maurizi E, Sabatelli S, Zauli A, Mason F, Audisio P (2017) Training of a dog for the monitoring of Osmoderma eremita. In: Carpaneto GM, Audisio P, Bologna MA, Roversi PF, Mason F (Eds) Guidelines for the Monitoring of the Saproxylic Beetles protected in Europe. Nature Conservation 20: 237-264. https://doi.org/10.3897/natureconservation.20.12688

Müller J, Jarzabek-Müller A, Bussler H, Gossner MM (2014) Hollow beech trees identified as keystone structures for saproxylic beetles by analyses of functional and phylogenetic diversity. Animal Conservation Animal Conservation 17: 154-162. https://doi.org/10.1111/acv.12075

Nardi G, Micó E (2010) Osmoderma cristinae. The IUCN Red List of Threatened Species 2010: e.T157875A5164314.

Nichols JD, Bailey LL, O’Connell AF Jr, Talancy NW, GrantEHC, Gilbert AT, Annand EM, Husband TP, Hines JE (2008) Multiscale occupancy estimation and modelling using multiple detection methods. Journal of Applied Ecology 45: 1321-1329. https://doi.org/10.1111/ j.1365-2664.2008.01509.x

Nieto A, Alexander KNA (2010) European Red List of Saproxylic Beetles. International Union for Conservation of Nature and Publications Office of the European Union, Luxembourg, 1-46. 
Nieto A, Mannerkoski I, Putchkov A, Tykarski P, Mason F, Dodelin B, Tezcan S (2010) Osmoderma eremita. The IUCN Red List of Threatened Species 2010: e.T15632A4926651. Downloaded on 07 November 2016.

Nüssler H (1986) Eine von Osmoderma eremita (Scop.) abweichende Weibchen-Form aus Südwestbulgarien (Insecta, Coleoptera, Scarabaeidae). Faunistiche Abhandlungen Staatlisches Museum für Tierkunde Dresden 13:113-117.

Oleksa A (2009) Conservation and ecology of the hermit beetle Osmoderma eremita s.l. in Poland. In: Buse J, Alexander KNA, Ranius T, Assmann T (Eds) Saproxylic Beetles - their role and diversity in European woodland and tree habitats. Proceedings of the $5^{\text {th }}$ Symposium and Workshop on the Conservation of Saproxylic Beetles. Pensoft Series Faunistica 89, 177-188.

Oleksa A, Gawronski R (2006) Forest insects in an agricultural landscape - presence of old trees is more important than the existence of nearby forest. Ecological Questions 7: 29-36.

Oleksa A, Ulrich W, Gawronski R (2007) Host tree preference of hermit beetles in a network of rural avenues in Poland (Osmoderma eremita Scop., Coleoptera: Scarabaeidae). Polish Journal of Ecology 55: 315-323. https://doi.org/10.1007/s10841-012-9499-7

Oleksa A, Chybicki IJ, Gawroński R, Svensson GP, Burczyk J (2013) Isolation by distance in saproxylic beetles may increase with niche specialization. Journal of Insect Conservation 17: 219-233.

Paulian R, Baraud J (1982) Faune des Coléoptères de France, II. Lucanoidea et Scarabaeoidea. Éditions Lechevalier, Paris, 477 pp.

Parisi V, Busetto A (1992) Scarabaeidae, Lucanidae, Cerambycidae. In: Zara (Ed.) Revisione dei coleotteri presenti nella collezione "A. Leosini". Museo di Storia Naturale, Università di Parma, Parma, 70 pp.

Pic M (1904) Les “Osmoderma” paléarctiques. L'Échange, Revue Linnéenne 20 (239): 83-84. Pignataro C, Vicidomini S (2007) Osmoderma italicum Sparacio (Coleoptera): ritrovato nei pressi del locus typicus dopo circa un secolo (Campania). Proceedings XXI Congresso Nazionale Italiano di Entomologia (Campobasso 11-16 Giugno 2007), Accademia Nazionale Italiana di Entomologia, 78.

Porta A (1932) Fauna Coleopterorum Italica. Vol. V, Rhynchophora-Lamellicornia. Stabilimento Tipografico Piacentino, Piacenza, 476 pp.

Prunier D (1999) Quelques observations sur la biologie d'Osmoderma eremita Scop. Le Coléopteriste 35: 23-24.

Ranius T (2000) Minimum viable metapopulation size of a beetle, Osmoderma eremita, living in tree hollows. Animal Conservation 3: 37-43. https://doi.org/10.1111/j.1469-1795.2000. tb00085.x

Ranius T (2001) Constancy and asynchrony of Osmoderma eremita populations in tree hollows. Oecologia 126: 208-215. https://doi.org/10.1007/s004420000515

Ranius T (2002a) Osmoderma eremita as an indicator of species richness of beetles in tree hollows. Biodiversity and Conservation 11: 931-941. https://doi. org/10.1023/A:1015364020043

Ranius T (2002b) Population ecology and conservation of beetles and pseudoscorpions living in hollow oaks in Sweden. Animal Biodiversity and Conservation 25: 53-68. 
Ranius T (2002c) Influence of stand size and quality of tree hollows on saproxylic beetles in Sweden. Biological Conservation 103: 85-91. https://doi.org/10.1016/S00063207(01)00124-0

Ranius T (2006) Measuring the dispersal of saproxylic insects: a key characteristic for their conservation. Population Ecology 48:177-188. https://doi.org/10.1007/s10144-006-0262-3

Ranius T (2007) Extinction risks in metapopulations of a beetle inhabiting hollow trees predicted from time series. Ecography 30: 716-726. https://doi.org/10.1111/j.2007.09067590.05134.x

Ranius T, Hedin J (2001) The dispersal rate of a beetle, Osmoderma eremita, living in tree hollows. Oecologia 126: 363-370. https://doi.org/10.1007/s004420000529

Ranius T, Jansson N (2000) The influence of forest regrowth, original canopy cover and tree size on saproxylic beetles associated with old oaks. Biological Conservation 95: 85-94. https:// doi.org/10.1016/S0006-3207(00)00007-0

Ranius T, Jansson N (2002) A comparison of three methods to survey saproxylic beetles in hollow oaks. Biodiversity and Conservation 11: 1759-1771.https://doi. org/10.1023/A:1020343030085

Ranius T, Nilsson SG (1997) Habitat of Osmoderma eremita Scop. (Coleoptera: Scarabaeidae), a beetle living in hollow trees. Journal of Insect Conservation 1: 193-204. https://doi. org/10.1023/A:1018416000766

Ranius T, Aguado LA, Antonsson K, Audisio P, Ballerio A, Carpaneto GM, Chobot K, Gjurašin B, Hanssen O, Huijbregts H, Lakatos F, Martin O, Neculiseanu Z, Nikitsky NB, Paill W, Pirnat A, Rizun V, Ruicãnescu A, Stegner J, Süda I, Szwalko P, Tamutis V, Telnov D, Tsinkevich V, Versteirt V, Vignon V, Vögeli M, Zach P (2005) Osmoderma eremita (Scopoli, 1763) (Coleoptera: Scarabaeidae: Cetoniinae) in Europe: a Short Summary of a PanEuropean Project. Proceedings of the 3th Symposium and Workshop on the Conservation of Saproxylic Beetles. Riga/Latvia, 07 $7^{\text {th }}-11^{\text {th }}$ July, 2004: 79-82.

Ranius T, Aguado L A, Antonsson K, Audisio P, Ballerio A, Carpaneto GM, Chobot K, Gjurašin B, Hanssen O, Huijbregts H, Lakatos F, Martin O, Neculiseanu Z, Nikitsky NB, Paill W, Pirnat A, Rizun V, Ruicãnescu A, Stegner J, Süda I, Szwalko P, Tamutis V, Telnov D, Tsinkevich V, Versteirt V, Vignon V, Vögeli M, Zach P (2005) Osmoderma eremita (Coleoptera: Scarabaeidae: Cetoniinae) in Europe. Animal Biodiversity and Conservation 28: 1-44.

Ranius T, Svensson GP, Berg N, Niklasson M, Larsson MC (2009) The successional change of hollow oaks affects their suitability for an inhabiting beetle, Osmoderma eremita. Annales Zoologici Fennici 46: 205-216. https://doi.org/10.5735/086.046.0305

R Core Team (2016). R: A language and environment for statistical computing. R Foundation for Statistical Computing, Vienna, Austria. URL https://www.R-project.org/

Redolfi De Zan L, Battisti C, Carpaneto GM (2014a) Bird and beetle assemblages in relict beech forests of central Italy: a multi-taxa approach to assess the importance of dead wood in biodiversity conservation. Community Ecology 15: 235-245. https://doi.org/10.1556/ ComEc.15.2014.2.12

Redolfi De Zan L, Bellotti F, D’Amato D, Carpaneto GM (2014b) Saproxylic beetles in three relict beech forests of central Italy: Analysis of environmental parameters and implications for forest management. Forest Ecology and Management 328: 229-244. https://doi. org/10.1016/j.foreco.2014.05.040 
Ritcher PO (1966) White Grubs and their Allies. A study of North American Scarabaeoid Larvae. Oregon State University Press, Corvallis, 219 pp.

Robertson BA, Hutto RL (2006) A framework for understanding ecological traps and an evaluation of existing evidence. Ecology 87: 1075-1085. https://doi.org/10.1890/00129658(2006)87[1075:AFFUET]2.0.CO;2

Ruffo S, Stoch F (Eds) (2005) Checklist e distribuzione della fauna italiana. Memorie del Museo Civico di Storia Naturale di Verona, Sezione Scienze della Vita 16: 1-307.

Schaffrath U (2003a) Zu Lebensweise, Verbreitung und Gefährdung von Osmoderma eremita (Scopoli, 1763) (Coleoptera; Scarabaeoidea, Cetoniidae, Trichiinae), Teil 1. Philippia 10: $157-248$.

Schaffrath U (2003b) Zu Lebensweise, Verbreitung und Gefährdung von Osmoderma eremita (Scopoli, 1763) (Coleoptera; Scarabaeoidea, Cetoniidae, Trichiinae), Teil 2. Philippia 10: 249-336.

Scholtz C, Grebennikov VV (2005) Scarabaeiformia (pp. 345-425). In: Beutel R, Leschen RAB, Handbook of Zoology, Volume 4: Arthropoda, Insecta; Volume 1: Coleoptera, Beetles: Morphology and systematics (Archostemata, Adephaga, Myxophaga, Polyphaga partim). Walter de Gruyter (Berlin): 1-567.

Schoolmeesters P (2016) Scarabs: World Scarabaeidae Database. In: Roskov Y, Abucay L, Orrell T, Nicolson D, Flann C, Bailly N, Kirk P, Bourgoin T, DeWalt RE, Decock W, De Wever A (Eds) Species 2000 \& ITIS Catalogue of Life, 28 ${ }^{\text {th }}$ September 2016. Species 2000, Naturalis, Leiden. http://www.catalogueoflife.org/col [version Jul 2016]

Shabalin SA, Bezborodov VG (2009) Larvae of Scarab Beetles of the Subfamily Trichiinae (Coleoptera, Scarabaeidae) from the Russian Far East. Zoologicheskii Zhurnal 88: 1201-1206. https://doi.org/10.1134/s0013873809090139

Šípek P, Fabrizi S, Eberle J, Ahrens D (2016a) Why Osmoderma is not a member of Trichiini and what else can we learn from a molecular phylogeny of rose chafers (Coleoptera: Scarabaeidae: Cetoniinae). Forschungs Museum Koenig, Bonn, April 2016. https://doi. org/10.13140/RG.2.1.4124.7603.

Šípek P, Fabrizi S, Eberle J, Ahrens D (2016b) A molecular phylogeny of rose chafers (Coleoptera: Scarabaeidae: Cetoniinae) reveals a complex and concerted morphological evolution related to their flight mode. Molecular Phylogenetics and Evolution 101: 163-175. https://doi.org/10.1016/j.ympev.2016.05.012

Smetana A (2006) Cetoniinae Leach, 1815. In: Löble I, Smetana A (Eds) Catalogue of Palaearctic Coleoptera, Volume 3: Scarabaeoidea - Scirtoidea - Dascilloidea - Buprestoidea Byrrhoidea. Apollo Books, Stenstrup, 283-313.

Smith ABT (2004) Clarification on the nomenclatural status of six genus-group names in the tribe Trichiini (Coleoptera: Scarabaeidae: Cetoniinae). The Coleopterists Bulletin 58(2): 285-291. https://doi.org/10.1649/704

Smith ABT, Hawks DC, Heraty JM (2006) An overview of the classification and evolution of the major scarab beetle clades (Coleoptera: Scarabaeoidea) based on preliminary molecular analyses. Coleopterists Society Monograph 5: 35-46. https://doi.org/10.1649/0010065X(2006)60[35:AOOTCA]2.0.CO;2

Sparacio I (1994) Osmoderma cristinae n. sp. di Sicilia (Insecta Coleoptera: Cetoniidae). Naturalista siciliano 17: 305-310. 
Sparacio I (2000) Osservazioni sulle Osmoderma Le Peletier et Audinet-Serville europee con descrizione di una nuova specie dell'Italia meridionale (Coleoptera Cetoniidae). Il Naturalista Siciliano 24 (3-4): 225-239.

Stegner J (2002) Der Eremit, Osmoderma eremita (Scopoli, 1763) (Col., Scarabaeidae), in Sachsen: Anforderungen an Schutzmaßnahmen für eine prioritäre Art der FFH-Richtlinie. Entomologische Nachrichten und Berichte 46: 213-238.

Straka U (2011). Untersuchungen zur Biologie des Juchtenkäfers (Osmoderma eremita Scopoli, 1763; Coleoptera) in Niederösterreich. Beiträge zur Entomofaunistik 12: 3-24.

Svensson GP, Larsson MC, Hedin J (2003) Air sampling of its pheromone to monitor the occurrence of Osmoderma eremita, a threatened beetle inhabiting hollow trees. Journal of Insect Conservation 7: 189-198. https://doi.org/10.1023/ B:JICO.0000020896.71333.f6

Svensson GP, Larsson MC, Hedin J (2004) Attraction of the larval predator Elater ferrugineus to the sex pheromone of its prey, Osmoderma eremita, and its implication for conservation biology. Journal of Chemical Ecology 30: 353-363. https://doi.org/10.1023/ B:JOEC.0000017982.51642.8c

Sverdrup-Thygeson A, Hanssen O, Ødegaard F (2010) Faglig grunnlag for handlingsplan for eremitt Osmoderma eremita. NINA Rapport 631: 1-44.

Tauzin P (1994a) Le genre Osmoderma Le Peletier et Audinet-Serville 1828 (Coleopt., Cetoniidae, Trichiinae, Osmodermatini). Systématique, biologie et distribution (Première partie). L'Entomologiste 50 (3): 195-214.

Tauzin P (1994b) Le genre Osmoderma Le Peletier et Audinet-Serville 1828 (Coleopt., Cetoniidae, Trichiinae, Osmodermatini). Systématique, biologie et distribution (Deuxième partie). L'Entomologiste 50: 217-242.

Tauzin P (1996) Complément à la note sur le genre Osmoderma (Coléoptères, Cetoniidae, Trichinae). L'Entomologiste 52: 105-106.

Tauzin P (2000) Localités connues de Osmoderma eremitum Scopoli en France. Le Coléoptériste 39: 133-136.

Tauzin P (2002) Osmoderma eremitum: complèments sur sa distribution en France et nouvelle information sur la taxonomie du genre (Coleoptera, Cetoniidae, Trichiinae, Osmodermatini). L'Entomologiste 58: 145-151.

Tauzin P (2005) Ethology and distribution of the "hermit beetle" in France. Cetoniimania 4: $131-153$.

Tauzin P (2006) Nouveau statut pour la variété castaneum de Osmoderma barnabita Motschoulsky, 1845 (Coleoptera, Scarabaeoidea, Cetoniidae, Trichiinae, Osmodermatini). Cetoniimania 1-2, 39-49.

Trizzino M, Audisio P, Bisi F, Bottacci A, Campanaro A, Carpaneto GM, Chiari S, Hardersen S, Mason F, Nardi G, Preatoni DG, Vigna Taglianti A, Zauli A, Zilli A, Cerretti P (2013) Gli artropodi italiani in Direttiva Habitat: biologia, ecologia, riconoscimento e monitoraggio. Quaderni Conservazione Habitat, 7. CFS-CNBFVR, Centro Nazionale Biodiversità Forestale. Cierre Grafica, Sommacampagna, Verona, 256 pp.

Van Emden van FI (1941) Larvae of British Beetles II. A key to the British Lamellicornia larvae. Entomological Monthly Magazine 77: 117-127, 181-192. 
Vernik M (2014) Collecting data of distribution for four Natura 2000 species of beetles (Coleoptera) in Slovenia (Poster), 4. Slovenski entomološki simpozij, 9. in 10. maja 2014, Fakulteti za naravoslovje in matematiko Univerze v Mariboru, Koroška. http://www.sporocivrsto.si

Vignon V (2006) Le pique-prune: histoire d'une sauvegard. Catiche Productions, Nohanent; Office de génie écologique, Saint-Maur_des_Fossés; Cofiroute, Sévres Cedex, France: 1-32.

Vignon V (2008) Comparing size of Osmoderma populations and habitat quality in different French localities: conservation perspectives. Revue d'Écologie (Terre et Vie) (supp. 10): 123-129.

Vignon V (2015) Parts of the life history of Osmoderma eremita's metapopulations in two study areas in the west of France (Coleoptera, Cetoniidae). Bulletin de la Société Entomologique Suisse 88: 39-48.

Vignon V, Orabi P (2003). Exploring the hedgerows network in the west of France for the conservation of saproxylic beetles (Osmoderma eremita, Gnorimus variabilis, Lucanus cervus, Cerambyx cerdo) (pp. 36-38) In: Bowen CP (Ed) Proceedings of the second pan-European conference on saproxylic beetles, Royal Holloway, University of London, 25th-27th June 2002. People's Trust for Endangered Species (London).

Vignon V, Asmode J-F, Rapaport P (2004) Heterogeneity of the spatial distribution of Osmoderma eremita (Scopoli, 1763) populations in a hedgerow network (France, Normandy). Proceedings of the $3^{\text {rd }}$ Symposium and Workshop on the Conservation of Saproxylic Beetles (Riga/Latvia, 07-11 July 2004): 109-115.

Vögeli M (2002) Der Eremit (Osmoderma eremita) in der Schweiz - eine naturschutzorientierte Analyse von Verbreitung und Habitat. Unveröffentlichte Diplomarbeit. Eidgenössische Technische Hochschule (Zürich).

Vrezec A, Pirnat A, Kapla A, Denac D (2008) Zasnova spremljanja stanja populacij izbranih ciljnih vrst hroščev vključno z dopolnitvijo predloga območij za vključitev v omrežje NATURA 2000. Morimus funereus, Rosalia alpina, Cerambyx cerdo, Osmoderma eremita, Limoniscus violaceus, Graphoderus bilineatus Nacionalni inštitut za biologijo (Ljubljana).

Vrezec A, Ambrožič Š, Kapla A (2012) An overview of sampling method tests for monitoring schemes of saproxylic beetles in the scope of Natura 2000 in Slovenia. In: Jurc M (Ed.) Saproxylic beetles in Europe: monitoring, biology and conservation. - Ljubljana: Slovenian Forestry Institute, Silva Slovenica, Studia Forestalia Slovenica 13: 73-90.

Vrezec A, Ambrožič Š, Kapla A, Bertoncelj I, Bordjan D (2014) Izvajanje spremljanja stanja populacij izbranih ciljnih vrst hroščev v letu 2013 in 2014. Končno poročilo. Nacionalni inštitut za biologijo (Ljubljana).

Westwood JO (1839) An Introduction to the modern classification of insects founded on the natural habits and corresponding organisation of the different families. Volume 1. Longman, Orme, Brown, Green, and Longmans (London): 1-462.

Winter S, Möller GC (2008) Microhabitats in lowland beech forests as monitoring tool for nature conservation. Forest Ecology and Management 255: 1251-1261. https://doi. org/10.1016/j.foreco.2007.10.029

Zauli A, Chiari S, Hedenstrom E, Svensson GP, Carpaneto GM (2014) Using odour traps for population monitoring and dispersal analysis of the threatened saproxylic beetles Osmoderma eremita and Elater ferrugineus in central Italy. Journal of Insect Conservation 18: 801-813. https://doi.org/10.1007/s10841-014-9687-8 
Zauli A, Carpaneto GM, Chiari S, Mancini E, Nyabuga FN, Redolfi De Zan L, Romiti F, Sabbani S, Audisio P, Hedenström E, Bologna MA, Svensson GP (2016a) Assessing the taxonomic status of Osmoderma cristinae (Coleoptera: Scarabaeidae), endemic to Sicily, by genetic, morphological and pheromonal analyses. Journal of Zoological Systematics and Evolutionary Research 54: 206-214. https://doi.org/10.1111/jzs.12127

Zauli A, Maurizi E, Carpaneto GM, Chiari S, Svensson G, Di Giulio A (2016b) Antennal fine morphology of the threatened beetle Osmoderma eremita (Coleoptera: Scarabaeidae), revealed by scanning electron microscopy. Microscopy Research and Technique 79: 178-191. https://doi.org/10.1002/jemt.22618

Zauli A, Maurizi E, Carpaneto GM, Chiari S, Merivee E, Svensson GP, Di Giulio A (2016c) Scanning electron microscopy analysis of the antennal sensilla in the rare saproxylic beetle Elater ferrugineus (Coleoptera, Elateridae). Italian Journal of Zoology 83: 338-350. https://doi.org/10.1080/11250003.2016.1211766

\section{Supplementary material I}

Scheme of protocol suggested by MIPP to monitoring the $O$. eremita population and list of materials to building the pheromone traps, BCWT

Authors: Emanuela Maurizi, Alessandro Campanaro, Stefano Chiari, Michela Maura, Fabio Mosconi, Simone Sabatelli, Agnese Zauli, Paolo Audisio, Giuseppe M. Carpaneto Data type: protocol

Copyright notice: This dataset is made available under the Open Database License (http://opendatacommons.org/licenses/odbl/1.0/). The Open Database License $(\mathrm{ODbL})$ is a license agreement intended to allow users to freely share, modify, and use this Dataset while maintaining this same freedom for others, provided that the original source and author(s) are credited.

Link: https://doi.org/10.3897/natureconservation.20.12685.suppl1

\section{Supplementary material 2}

\section{Field sheet to fill during each survey and its legend}

Authors: Emanuela Maurizi, Alessandro Campanaro, Stefano Chiari, Michela Maura, Fabio Mosconi, Simone Sabatelli, Agnese Zauli, Paolo Audisio, Giuseppe M. Carpaneto Data type: field sheet

Copyright notice: This dataset is made available under the Open Database License (http://opendatacommons.org/licenses/odbl/1.0/). The Open Database License $(\mathrm{ODbL})$ is a license agreement intended to allow users to freely share, modify, and use this Dataset while maintaining this same freedom for others, provided that the original source and author(s) are credited.

Link: https://doi.org/10.3897/natureconservation.20.12685.suppl2 